\title{
A comparative study of the response of modeled non-drizzling stratocumulus to meteorological and aerosol perturbations
}

\author{
J. L. Petters ${ }^{1}$, H. Jiang ${ }^{2}$, G. Feingold ${ }^{3}$, D. L. Rossiter ${ }^{1}$, D. Khelif ${ }^{4}$, L. C. Sloan ${ }^{1}$, and P. Y. Chuang ${ }^{1}$ \\ ${ }^{1}$ Earth and Planetary Sciences Department, University of California - Santa Cruz, Santa Cruz, CA, USA \\ ${ }^{2}$ Cooperative Institute for Research in the Atmosphere, Fort Collins, CO, USA \\ ${ }^{3}$ NOAA/Earth System Research Laboratory, Boulder, CO, USA \\ ${ }^{4}$ Department of Mechanical and Aerospace Engineering, University of California - Irvine, Irvine, CA, USA
}

Correspondence to: J. L. Petters (jlpetter@ucsc.edu)

Received: 4 September 2012 - Published in Atmos. Chem. Phys. Discuss.: 16 October 2012

Revised: 14 February 2013 - Accepted: 22 February 2013 - Published: 5 March 2013

\begin{abstract}
The impact of changes in aerosol and cloud droplet concentration $\left(N_{\mathrm{a}}\right.$ and $\left.N_{\mathrm{d}}\right)$ on the radiative forcing of stratocumulus-topped boundary layers (STBLs) has been widely studied. How these impacts compare to those due to variations in meteorological context has not been investigated in a systematic fashion for non-drizzling overcast stratocumulus. In this study we examine the impact of observed variations in meteorological context and aerosol state on daytime, non-drizzling overcast stratiform evolution, and determine how resulting changes in cloud properties compare.

Using large-eddy simulation (LES) we create a model base case of daytime southeast Pacific coastal stratocumulus, spanning a portion of the diurnal cycle (early morning to near noon) and constrained by observations taken during the VOCALS (VAMOS Ocean-Atmosphere-Land Study) field campaign. We perturb aerosol and meteorological properties around this base case to investigate the stratocumulus response. We determine perturbations in the cloud top jumps in potential temperature $\theta$ and total water mixing ratio $q_{\mathrm{t}}$ from ECMWF Re-analysis Interim data, and use a set of $N_{\mathrm{d}}$ values spanning the observable range. To determine the cloud response to these meteorological and aerosol perturbations, we compute changes in liquid water path (LWP), bulk optical depth $(\tau)$ and cloud radiative forcing (CRF).

We find that realistic variations in the thermodynamic jump properties can elicit a response in the cloud properties of $\tau$ and shortwave (SW) CRF that are on the same order of magnitude as the response found due to realistic changes in aerosol state (i.e $N_{\mathrm{d}}$ ). In response to increases in $N_{\mathrm{d}}$, the cloud layer in the base case thinned due to increases
\end{abstract}

in evaporative cooling and entrainment rate. This cloud thinning somewhat mitigates the increase in $\tau$ resulting from increases in $N_{\mathrm{d}}$. On the other hand, variations in $\theta$ and $q_{\mathrm{t}}$ jumps did not substantially modify $N_{\mathrm{d}}$. The cloud layer thickens in response to an increase in the $\theta$ jump and thins in response to an increase in the $q_{\mathrm{t}}$ jump, both resulting in a $\tau$ and $\mathrm{SW}$ $\mathrm{CRF}$ response comparable to those found from perturbations in $N_{\mathrm{d}}$. Longwave CRF was not substantially altered by the perturbations we tested.

We find that realistic variations in meteorological context can elicit a response in CRF and $\tau$ on the same order of magnitude as, and at times larger than, that response found due to realistic changes in aerosol state. We estimate the limits on variability of cloud top jump properties required for accurate observation of aerosol SW radiative impacts on stratocumulus, and find strict constraints: less than $1 \mathrm{~K}$ and $1 \mathrm{~g} \mathrm{~kg}^{-1}$ in the early morning hours, and order $0.1 \mathrm{~K}$ and $0.1 \mathrm{~g} \mathrm{~kg}^{-1}$ close to solar noon. These constraints suggest that accurately observing aerosol radiative impacts in stratocumulus may be challenging as co-variation of meteorological properties may obfuscate aerosol-cloud interactions.

\section{Introduction}

Marine boundary layer stratiform clouds are persistent and prevalent (Klein and Hartmann, 1993), imparting a strong negative forcing to the Earth's radiative budget (Chen et al., 2000). The representation of these clouds in current climate models is relatively poor, leading to large uncertainty in 
climate projections (Randall et al., 2007). The difficulty in representing stratiform clouds in large-scale models is exacerbated by their sensitivity to changes in aerosol state and in the "meteorological context" in which the cloud system resides.

The impacts of perturbations in aerosol state on the radiative properties of stratiform cloud systems have been widely studied. These studies have focused on changes in cloud optical properties (e.g. Twomey and Wojciechowski, 1969; Twomey, 1977; Coakley et al., 1987) and changes in cloud system evolution (e.g. Albrecht, 1989). The impact of aerosol on stratiform cloud has been of particular interest and has been extensively studied with models (e.g. Jiang et al., 2002; Ackerman et al., 2004; Lu and Seinfeld, 2005; Wood, 2007; Bretherton et al., 2007; Sandu et al., 2008; Hill et al., 2008; Petters et al., 2012), remote sensing (e.g. Nakajima et al., 1991; Han et al., 1998; Sekiguchi et al., 2003; Kaufman et al., 2005; Quaas et al., 2006; Painemal and Zuidema, 2010) and in-situ observations (e.g. Brenguier et al., 2000; Durkee et al., 2000; Twohy et al., 2005; Ghate et al., 2007; Lu et al., 2007). Other recent studies have focused more attention on the the impact that meteorological context can have on aerosol-cloud interactions (Matsui et al., 2006; George and Wood, 2010; Painemal and Zuidema, 2010; Wang et al., 2010; Mechem et al., 2012).

We define "meteorological context" as those large-scale features of the atmosphere and surface that influence the stratiform cloud system on the time scale of interest (which in this study is less than 1 day) that are not strongly influenced by cloud evolution. For example, solar insolation, largescale subsidence rate and the boundary layer jump properties would be considered part of this meteorological context. In contrast, the temperature and humidity of the boundary layer are not part of this context because they can respond rapidly to changes in the cloud.

Variations in this meteorological context can substantially influence the evolution of stratiform cloud systems. For example, changes in the potential temperature $(\theta)$ jump strength can influence entrainment mixing (Lilly, 1968; Sullivan et al., 1998), while changes in free tropospheric moisture content (free tropospheric $q_{\mathrm{t}}$ ) can lead to changes in the amount of evaporative cooling due to entrainment (Ackerman et al., 2004). The meteorological context also can influence the radiative forcing of these cloud systems. Increasing aerosol concentration $N_{\mathrm{a}}$ can lead to reductions in liquid water path (LWP) when low relative humidity air resides above the boundary layer (Ackerman et al., 2004). The thermodynamic structure of the sub-cloud layer can influence the fraction of drizzle reaching the surface, which in turn can influence boundary layer dynamics and cloud evolution (Feingold et al., 1996; Ackerman et al., 2009).

Furthermore, these variations can also potentially obfuscate the impact of aerosol on cloud evolution. The results of Matsui et al. (2006) suggest aerosol perturbations on cloud radiative forcing of stratiform cloud systems could not be studied in isolation; thermodynamics and the diurnal cycle also should be taken into account. Using satellite and reanalysis data, George and Wood (2010) found that variability in cloud microphysics contributed to less than $10 \%$ of the variability in observed albedo in a stratocumulus-dominated region. Variability in albedo was mostly related to variability in LWP and cloud fraction. Additionally, because meteorological and aerosol states are dependent on air-mass history, the two states tend to correlate in observations (Stevens and Feingold, 2009). For example, during the 2nd Aerosol Characterization Experiment (ACE-2, Brenguier et al., 2003) it was found that low aerosol concentrations were correlated with cool, moist maritime air masses while high aerosol concentrations were correlated with warm, dry continental air masses.

For these many reasons it can be difficult to disentangle the changes in the aerosol state and meteorological context in order to isolate the aerosol forcing (Stevens and Feingold, 2009). In observational studies, it is typically assumed that the meteorological context is approximately constant during the observational period so changes in cloud evolution are primarily determined by changes in aerosol. How constant the meteorological context must be for this assumption to be valid remains an open question. In modeling studies of aerosol-cloud interactions in stratiform cloud systems, the initial meteorological context can be set constant, thereby removing its potential to influence cloud evolution. Analyses of the sensitivity to meteorological context exist in some modeling studies (e.g. Jiang et al., 2002; Sandu et al., 2008), and in this study we expand upon such analyses.

In this study we examine how stratiform cloud systems are affected by variability in meteorological context and aerosol state and evaluate their comparative importance. Specifically, we address the following questions:

Q1 Given observed variations in meteorological context $\Delta m$ and aerosol state $\Delta a$, how do the resulting changes in stratiform cloud properties $\Delta c$ compare?

Q2 What physical processes and interactions lead to these changes in cloud?

We use a numerical modeling framework for this study because we can independently vary meteorological context and aerosol state. Using large-eddy simulation (LES), we investigate stratiform cloud evolution and the response of this evolution to variations in meteorological and aerosol changes. We determine realistic variations in meteorological context $\Delta m$ through use of European Centre for MediumRange Weather Forecasting (ECMWF) Re-analysis Interim (ERA-Interim) data (Uppala et al., 2005, 2008).

For objective comparison of the cloud evolution to variations in meteorological context $\Delta m$ and aerosol state $\Delta a$, we compute the response of the cloud properties $(\Delta c)$ of $\tau$ and LWP. Because we simulate a daytime portion of the diurnal cycle, we also directly compute the response of 
Table 1. Model base case configuration and settings for Regional Atmospheric Modeling System (RAMS) in large-eddy simulation. Where applicable, configuration values are based on in-situ observations from the Twin Otter.

\begin{tabular}{|c|c|c|}
\hline Model Part & Setting & Notes/Reference \\
\hline grid resolution & $\begin{array}{l}50 \mathrm{~m} \text { horizontal, } 10 \mathrm{~m} \text { vertical refined to } 5 \mathrm{~m} \\
\text { near boundary layer top }\end{array}$ & $\begin{array}{l}\text { vertical resolution consistent with Stevens et al. } \\
\text { (2005) }\end{array}$ \\
\hline domain size & $3.4 \mathrm{~km}$ on a side, $2 \mathrm{~km}$ in vertical & $\begin{array}{l}\text { simulates one full convective cell (Caldwell and } \\
\text { Bretherton, 2009) }\end{array}$ \\
\hline boundaries & $\begin{array}{l}\text { cyclic lateral boundary conditions, rigid bottom } \\
\text { and top }\end{array}$ & $\begin{array}{l}\text { Rayleigh friction layer in top } 16 \text { vertical layers } \\
\text { for removal of spurious gravity wave reflection }\end{array}$ \\
\hline model timestep & $0.5 \mathrm{~s}$ for model spin-up, $1 \mathrm{~s}$ thereafter & meets CFL criterion \\
\hline microphysics parameterization: & bin microphysical model & $\begin{array}{l}\text { (Tzivion et al., 1987; Feingold et al., 1988; } \\
\text { Tzivion et al., 1989), described in Feingold } \\
\text { et al. (1996); Stevens et al. (1996) }\end{array}$ \\
\hline \multirow{5}{*}{ radiation parameterization: } & 25 bins for non-drizzling case & mass-doubling between bins \\
\hline & two-stream solver & (Harrington, 1997) \\
\hline & correlated-k distribution spectral band model & $\begin{array}{l}15 \text { shortwave and } 12 \text { longwave spectral inter- } \\
\text { vals (Cole, 2005) }\end{array}$ \\
\hline & binned cloud optical properties & (Harrington and Olsson, 2001) \\
\hline & thermodynamic profile above domain & $\begin{array}{l}\text { Iquique, Chile sounding from } 12: 00 \mathrm{Z}, 19 \mathrm{Oc}- \\
\text { tober } 2008\end{array}$ \\
\hline radiative timestep & $5 \mathrm{~s}$ & meets strict criterion of Xu and Randall (1995) \\
\hline sub-grid scale parameterization & Deardorff isotropic diffusion scheme & (Deardorff, 1980) \\
\hline subsidence & $5 \times 10^{-6} \cdot \mathrm{zm} \mathrm{s}^{-1}$ & $\begin{array}{l}\mathrm{z} \text { is height; expression follows Ackerman et al. } \\
\text { (2009), coefficient chosen for best match to ob- } \\
\text { servations of boundary-layer height }\end{array}$ \\
\hline sea surface temperature & constant $289.7 \mathrm{~K}$ & $\begin{array}{l}\text { as measured from Twin Otter for non-drizzling } \\
\text { case, used for radiative computation only }\end{array}$ \\
\hline surface fluxes & $\begin{array}{l}\text { constant } 3 \text { and } 27 \mathrm{~W} \mathrm{~m}^{-2} \text { for sensible/latent } \\
\text { fluxes }\end{array}$ & as measured from Twin Otter \\
\hline
\end{tabular}

cloud radiative forcing $(\mathrm{CRF})$ to variations in meteorological context and aerosol state and see how this response compares to the other two. Many modeling studies of aerosolcloud interactions on stratocumulus simulate nighttime cloud evolution (e.g. Bretherton et al., 2007; Hill et al., 2008) and as such rely on modeled response in $\tau$ to determine the importance of aerosol's influence on CRF. To serve as the model base case for this comparative study, we first create a observationally-constrained LES of non-drizzling overcast stratocumulus based on in-situ observations taken from the CIRPAS (Center for Interdisciplinary RemotelyPiloted Aircraft Studies) Twin Otter during the VOCALS (VAMOS Ocean-Atmosphere-Land Study) field campaign (Wood et al., 2011). Describing the LES model description and configuration, the observations used to create the model base case, and the comparison between LES output and observations (Sects. 2 to 4 ) comprise the first part of this study. In the second part we detail the comparative study, including the experimental design, model output and computed responses (Sects. 5 to 7 ).

We find that realistic variations in meteorological context can elicit a response in CRF and $\tau$ on the same order of magnitude as, and at times larger than, those responses found due to realistic changes in aerosol state. Our results suggest that careful consideration of consistency in meteorological context (the jump properties in particular) must be given when planning observational studies of aerosol-cloud interactions and their impact on stratocumulus radiative properties.

\section{Model description}

Large-eddy simulation (LES) is a commonly used numerical technique for studying cloud-topped boundary layers. Because it is capable of resolving turbulent motions and the interactions among microphysics, radiation, and dynamics (Stevens et al., 2005; Ackerman et al., 2009; Stevens and Feingold, 2009), it is the most applicable numerical tool for our study. Other cloud-scale numerical modeling techniques (e.g. Harrington et al., 2000; Pinsky et al., 2008) require dynamical motions as inputs. Hence the meteorological context cannot be varied within these models, and interactions between dynamics and either radiation or microphysics cannot be represented.

Here we use the Regional Atmospheric Modeling System (RAMS, Cotton et al., 2003) version 4.3.0 configured for LES mode (see Stevens et al., 1998; Jiang et al., 2002). The model configuration and routines we use within 
RAMS are specified in Table 1. Wang et al. (2010) and Mechem et al. (2012) used LES in their respective studies of aerosol and meteorological forcings in stratocumulus. However, they focused their studies on the mesoscale organization of stratocumulus (i.e. open and closed cells), simulating larger regions with both coarser spatial resolution and longer timescales than we do in this study.

We use a bin microphysical model (Feingold et al., 1996; Stevens et al., 1996) in order to best reproduce observed drop size distributions. This particular microphysical model has been previously used for several studies of aerosol-cloud interactions within the boundary layer (e.g. Jiang et al., 2002; Xue and Feingold, 2006; Hill et al., 2009). In this model aerosol is assumed to be fully-soluble ammonium sulfate with a lognormal size distribution that is constant over time and space (Xue and Feingold, 2006). For the base case the mean aerosol diameter $\bar{D}_{\mathrm{p}}$ is $0.12 \mu \mathrm{m}$. We use a total aerosol concentration $N_{\mathrm{a}}=450 \mathrm{~cm}^{-3}$, giving an initial average cloud droplet concentration value $N_{\mathrm{d}}=425 \mathrm{~cm}^{-3}$, matching the mean value from aircraft observations on the VOCALS case study that we are simulating (see next section).

In this study we simulate only overcast, or nearly overcast, stratocumulus. There are a few reasons for this constraint. First, our large-eddy simulations assume homogenous mixing within model grid-boxes. While Hill et al. (2009) did not find this assumption to substantially influence the LWP and cloud optical depth of a modeled overcast stratocumulus layer, it may be expected to be more impactful in simulation of a thin, broken stratocumulus layer. Second, the radiation parameterization we use (Harrington, 1997) employs the Independent Column Approximation (ICA), in which radiation is not exchanged between model columns. Use of the ICA could lead to biases in both computations of cloud radiative heating and cloud radiative forcing (e.g. Zuidema et al., 2008), especially at model resolutions used in our study (Cahalan et al., 2005). Finally, large-eddy simulations coupled with a bin microphysical model are computationally intensive, and simulating more than a a fraction of the stratocumulus diurnal cycle is impractical. For these reasons our simulations end when our observationally-constrained model cloud layer begins to break up (i.e. cloud fraction becomes less than unity).

Schubert et al. (1979) determined two separate response timescales for the STBL; one of thermodynamic adjustment (changes in water vapor mixing ratio $q_{\mathrm{v}}$ and cloud base, for example) on a timescale of less than a day, and one for the inversion height, adjusting on timescales of 2 to 5 days. Bretherton et al. (2010) showed that STBLs simulated with LES or mixed-layer models evolve to equilibrium states (thin, broken cloud or thick, overcast cloud) over the course of several days, and these equilibria are dependent on the initial inversion height. The findings of Bretherton et al. (2010) suggest that the cloud response to perturbations in meteorology and aerosol might be less important on longer timescales than those investigated here because changes in inversion height, driven by changes in large-scale subsidence, might play the primary role. Thus our results are most applicable to the shorter thermodynamic adjustment timescale. We simulate stratocumulus evolution during daytime hours, corresponding to the time of the observations and during which changes in cloud properties are most relevant to shortwave (SW) radiative forcing.

While LES is the most appropriate tool for this study, like any model, it has imperfections and limitations. One issue common to LES of the stratocumulus-topped boundary layer (STBL) is their propensity to over-entrain air across the cloud top interface (Stevens et al., 2005; Caldwell and Bretherton, 2009). Sub-grid scale parameterizations commonly used in LES simplify many small-scale processes important in STBL entrainment (e.g. Mellado, 2010), and one consequence of this simplification is over-entrainment. Below we describe measures to lessen the impact of this over-entrainment on our modeling output.

\section{Observations}

To build a realistic, observationally-based large-eddy simulation of stratocumulus, i.e. the model base case, we use in-situ observations taken from the CIRPAS Twin Otter during the VOCALS (VAMOS Ocean-Atmosphere-Land Study) field campaign. We focus on a simpler non-drizzling case because the existence of drizzle increases the complexity of the evolution of microphysics and dynamics in the STBL (Lu et al., 2007; Ackerman et al., 2009). During VOCALS, drizzle in the coastal stratocumulus observed from the Twin Otter was negligible $\left(\ll 0.1 \mathrm{~mm} \mathrm{day}^{-1}\right)$.

Table 2 briefly describes the relevant instrumentation on board and parameters observed by the Twin Otter during VOCALS. Of particular note is the Phase-Doppler Interferometer (PDI), which provides detailed microphysical information about the cloud layer (Chuang et al., 2008). The PDI measures the drop size distribution for a size range from 2.0 to $150 \mu \mathrm{m}$ in 128 bins. Phase-Doppler Interferometer integrated liquid water content (LWC) has been previously compared with LWC as measured from the Gerber PVM-100 (Chuang et al., 2008). Because of the relatively low efficiency with which the PVM-100 samples droplets larger than $\sim 30$ to $40 \mu \mathrm{m}$ (Wendisch et al., 2002), we use the PDIderived LWC in our study. Sampling of the cloud droplet distribution with the PDI also covers a broader size range more appropriate for comparisons with the LES. Because of the low drizzle rates, the contribution to LWC by drops larger than $100 \mu \mathrm{m}$ is negligible.

For the base case, we simulate VOCALS observations from the CIRPAS Twin Otter on 19 October 2008, research flight 03 . These in-situ observations were taken in the vicinity of $20^{\circ} \mathrm{S}, 72^{\circ} \mathrm{W}$, a few hundred $\mathrm{km}$ west of the Chilean coast, at 09:00 to 11:30 local time (12:00 to 14:30 UTC). All 
Table 2. Aerosol and cloud instrument payload on Twin Otter during field campaigns. Abbreviated list; only instruments referenced in this article are listed.

\begin{tabular}{llll}
\hline Parameter & Instrument & Measured at & Range Detected/Error \\
\hline Liquid Water Content & Gerber PVM-100 & $10 \mathrm{~Hz}$ & $<40 \mu \mathrm{m}(\mathrm{nominal})$ \\
Cloud Droplet Size Distribution & Phase Doppler Interferometer (PDI) & $1 \mathrm{to} 10 \mathrm{~Hz}$ & $2-100 \mu \mathrm{m}$ \\
Drizzle Size Distribution & Cloud Imaging Probe (CIP) & $1 \mathrm{~Hz}$ & $100-2000 \mu \mathrm{m}$ \\
Accumulation-mode Aerosol Size Distribution & Passive Cavity Aerosol Spectrometer (PCASP) & $1 \mathrm{~Hz}$ & $0.1-2.6 \mu \mathrm{m}$ \\
Particle Number Concentration & TSI Condensation Particle Counter (CPC) 3010 & $10 \mathrm{~Hz}$ & $\mathrm{diameter}>10 \mathrm{~nm}$ \\
Turbulent velocities & Nose-mounted gust probe & $100 \mathrm{~Hz}$ & $\pm 0.1 \mathrm{~m} \mathrm{~s} \mathbf{s}^{-1}$ \\
Ambient Temperature & Rosemount & $10 \mathrm{~Hz}$ & -50 to $50, \pm 0.1^{\circ} \mathrm{C}$ \\
Dew Point Temperature & EdgeTech chilled mirror & $1 \mathrm{~Hz}$ & -50 to $50, \pm 0.2^{\circ} \mathrm{C}$ \\
Water Vapor Content & Li-Cor & $20 \mathrm{~Hz}$ & 0 to $42 \pm 0.005 \mathrm{~g} \mathrm{~m}^{-3}$ \\
Sea Surface Temperature & Heitronics KT 19.85 Pyrometer & $10 \mathrm{~Hz}$ & $-5 \mathrm{to} 45^{\circ} \mathrm{C}$ \\
Barometric Pressure & Setra barometric transducers & $100 \mathrm{~Hz}$ & $600-1100 \pm 75 \mathrm{mb}$ \\
\hline
\end{tabular}

Table 3. Thermodynamic profile (sounding) used to initialize model. Where applicable, original values from observations (before modification for use in this study) are shown in parentheses. The surface pressure was initialized at $1018.0 \mathrm{mb}$. Temperature and moisture values above the inversion were those observed immediately before the flight legs.

\begin{tabular}{lccrr}
\hline Layer & $\begin{array}{c}\text { Potential } \\
\text { Temperature }(\mathrm{K})\end{array}$ & $\begin{array}{c}\text { Total Water } \\
\text { Content }\left(\mathrm{g} \mathrm{kg}^{-1}\right)\end{array}$ & $\begin{array}{r}\text { U wind } \\
\left(\mathrm{m} \mathrm{s}^{-1}\right)\end{array}$ & $\begin{array}{r}\mathrm{V} \text { wind } \\
\left(\mathrm{m} \mathrm{s}^{-} 1\right)\end{array}$ \\
\hline $0-980 \mathrm{~m}(0-1040 \mathrm{~m})$ & 287.30 & $7.55(7.35)$ & -0.50 & 0.70 \\
$990 \mathrm{~m}(1050 \mathrm{~m})$ & 293.65 & $4.17(4.07)$ & 0.55 & -0.50 \\
$1000 \mathrm{~m}(1060 \mathrm{~m})$ & 300.00 & 0.80 & 1.60 & -1.70 \\
above $1000 \mathrm{~m}(1050 \mathrm{~m})$ & observed & observed & 1.60 & -1.70 \\
\hline
\end{tabular}

observations are averaged to $1 \mathrm{~Hz}$ (for a horizontal resolution of $55 \mathrm{~m}$ ) over five $\sim 30 \mathrm{~km}$ flight legs: two below-cloud (both near the surface), one just below cloud base, and two in-cloud (mid-cloud and cloud top). During this day a STBL with cloud of $\sim 300 \mathrm{~m}$ thickness was observed, and the LWC increased nearly adiabatically with height. We compared the atmospheric profiles taken before and after the flight legs and found little change in the thermodynamic and wind profiles. Averaged over the depth of the boundary layer, the profiles exhibited the following changes during the observational period: $0.2 \mathrm{~K}$ decrease in $\theta, 0.16 \mathrm{~g} \mathrm{~kg}^{-1}$ increase in $q_{\mathrm{v}}, 1.0 \mathrm{~m} \mathrm{~s}^{-1}$ increase in easterly wind speed, and $0.7 \mathrm{~m} \mathrm{~s}^{-1}$ increase in northernly wind speed. The inversion height remained fairly constant over the observational period, indicating that net entrainment or detrainment in the boundary layer was negligible. Vertical profiles of vertical velocity and equivalent potential temperature show that the observed STBL is well-mixed. Taken together, these STBL properties provide us with a "canonical" stratocumulus case to model with LES; that is, a case that has similar characteristics to those previously studied with LES (e.g. Dyunkerke et al., 2004; Stevens et al., 2005).

Potential temperature and moisture content jumps at the cloud top interface were $+12.7 \mathrm{~K}$ and $-6.55 \mathrm{~g} \mathrm{~kg}^{-1}$, respectively. The Passive Cavity Aerosol Spectrometer Probe (PCASP) showed sub-cloud accumulation mode aerosol concentrations elevated from those expected for clean maritime conditions $\left(\sim 600 \mathrm{~cm}^{-3}\right)$, at least partially accounting for the low drizzle rates. Observed average sea surface temperature and surface flux values are shown in Table 1.

\section{Comparing model performance to observations}

The sounding data used to initialize the model are described in Table 3. We initialized the base simulation at 07:30 UTC, five hours prior to the hour of the five $\sim 30 \mathrm{~km}$ flight legs, giving the LES ample time to spin-up realistic boundary layer eddies. Because of this time difference, we found it necessary to modify the sounding data from that taken by the Twin Otter so that the simulated boundary layer would reasonably compare to that observed. These modifications, also shown in Table 3, were (a) increasing $q_{\mathrm{t}}$ content in the boundary layer by $0.2 \mathrm{~g} \mathrm{~kg}^{-1}$ (a $3 \%$ increase over the measured value, and (b) lowering the height of the inversion by $60 \mathrm{~m}$ (from $1040 \mathrm{~m}$ to $980 \mathrm{~m}$ ).

Furthermore, we require thermodynamic profile data from the top of the model domain $(2 \mathrm{~km})$ to the top of the atmosphere (TOA) for accurate radiative computations. We use the $12 \mathrm{Z}$ sounding from Iquique, Chile on the same day as the flight observations were taken. Using the Iquique sounding ensured that free tropospheric $q_{\mathrm{t}}$ values in the simulation were similar to those during the observational period. From $16 \mathrm{~km}$ up to TOA $(103 \mathrm{~km})$ we determined the 

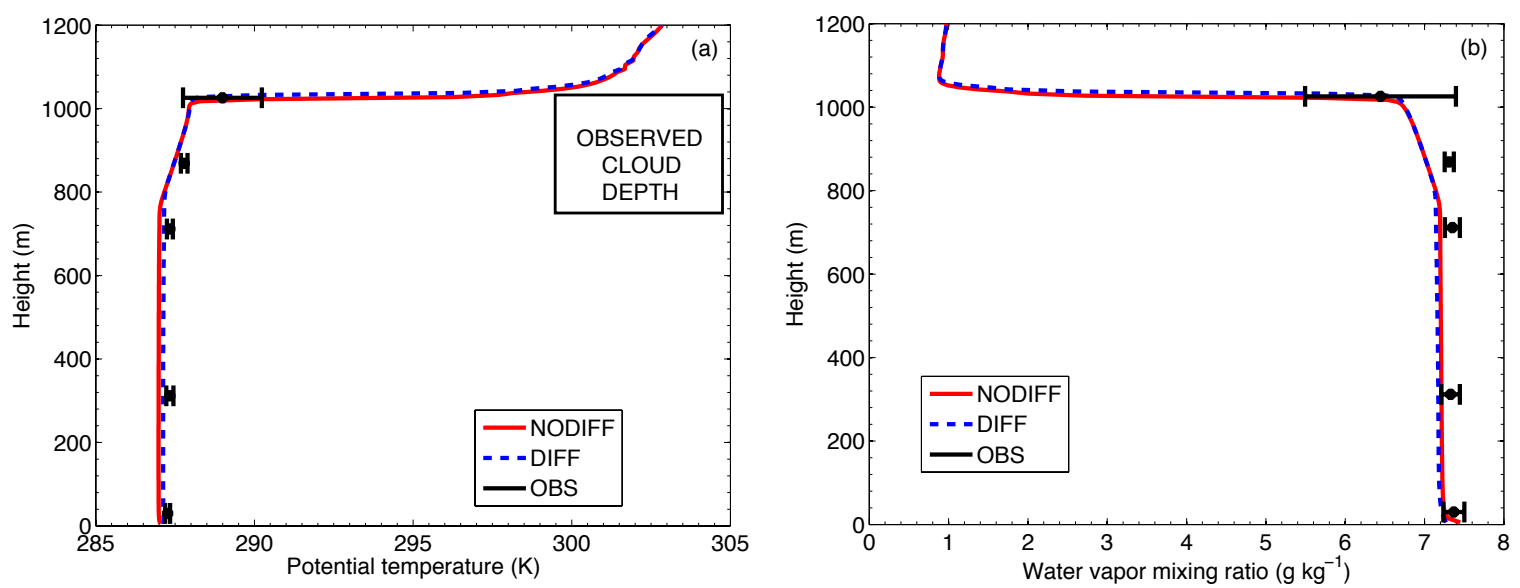

Fig. 1. Comparison of thermodynamic profiles between CIRPAS in-situ observations (data points) and LES output (lines). Observations show mean (symbol) and standard deviations (error bars) over each of the five flight legs. LES output are domain-averaged and temporally averaged over the sixth hour of simulation. Times of observations and LES output coincide.

thermodynamic profile from interpolation of profiles from McClatchy et al. (1971), as typically done in RAMS. Interpolation between the McClatchy et al. (1971) subtropical winter and subtropical summer profiles by time of year was used to create an appropriate subtropical profile for 19 October 2008. Latitudinal interpolation between that resulting profile and the McClatchy et al. (1971) tropical profile was used to create a profile appropriate for $20^{\circ} \mathrm{S}$.

Figures 1 through 3 show comparisons of profiles from the LES and observations. For the LES we show output from two simulations: one in which sub-grid diffusion of scalars (e.g. moisture, energy) is accounted for (DIFF); and one in which this sub-grid diffusion is neglected (NODIFF). Stevens et al. (2005), in a large LES intercomparison and performance study, suggest that neglecting the sub-grid diffusion of scalars leads to a more well-mixed model STBL and better agreement with observations by reducing the impact of over-entrainment common to LES. Nominally the subgrid scheme ensures that fluxes of energy and moisture remain constant with changes in model grid resolution; hence the primary disadvantage of neglecting sub-grid diffusion of scalars is that simulation output can exhibit dependency on changes in model grid resolution (Stevens et al., 2005). We deemed this possible modification to be acceptable if it resulted in better agreement between the model and observations in our case. Furthermore, Cheng et al. (2010) have found that, even with the full use of the sub-grid scheme, boundary layer cloud LES output are resolution dependent.

The $\theta$ and $q_{\mathrm{v}}$ profiles as observed on the flight legs are reasonably represented by the LES (Fig. 1a, b). Encouragingly, all model profiles show a well-mixed boundary layer similar to that observed. For both simulations, domain-averaged model $\theta$ (by $0.1 \mathrm{~K}$ for DIFF and $0.2 \mathrm{~K}$ for NODIFF) and model $q_{\mathrm{v}}$ (by $0.24 \mathrm{~g} \mathrm{~kg}^{-1}$ for DIFF and $0.21 \mathrm{~g} \mathrm{~kg}^{-1}$ for NODIFF, both by $3 \%$ ) in the boundary layer are biased low as compared to the observations. Note that all quantitative comparisons between model and observations are between plotted mean values only. The neglect of sub-grid diffusion of scalars leads to a small decrease in $\theta$ and small increase in $q_{\mathrm{v}}$ within the boundary layer. This is expected because mixing of warmer and drier free tropospheric air into the boundary layer is reduced when this diffusion of scalars is neglected.

To determine how well the two LES configurations represent observed dynamical properties, we examine resolvedscale profiles of vertical velocity variance, buoyancy production of turbulent kinetic energy (TKE) and total water flux. Vertical velocity variance $\left(\overline{w^{\prime} w^{\prime}}\right)$, or the vertical component of TKE, is a useful proxy for the strength of circulations within the STBL. For the highest and lowest of the five aircraft altitudes ( $30 \mathrm{~m}$ and $1025 \mathrm{~m}$ ), the DIFF and NODFF simulations exhibit very little difference. In both cases, observed $\overline{w^{\prime} w^{\prime}}$ compares reasonably with modeled values. For the two flight legs at 710 and $870 \mathrm{~m}$, observed values match well with NODIFF (underestimated by $8 \%$ ), and are underestimated by $24 \%$ and $12 \%$, respectively, by DIFF. For the flight leg at $310 \mathrm{~m}$ altitude both simulations underestimate $\overline{w^{\prime} w^{\prime}}$ by a factor of 2 (by $54 \%$ for DIFF and $46 \%$ for NODIFF). NODIFF shows better agreement with observations, since this particular configuration results in less entrainment of free tropospheric air and a smaller buoyancy sink of boundary layer TKE (Stevens et al., 2005). Thus more energy is available to drive STBL circulations.

Investigation of profiles of buoyancy production of TKE and total water flux (Fig. 3) reveal small differences between the two LES configurations. In the convective STBL, buoyancy production of TKE is an important source term in the TKE budget (Nicholls, 1989). Radiative cooling at cloud top leads to negatively buoyant parcels that propagate downward, driving STBL circulations. We find that buoyancy production of TKE within cloud increases only slightly when sub-grid 


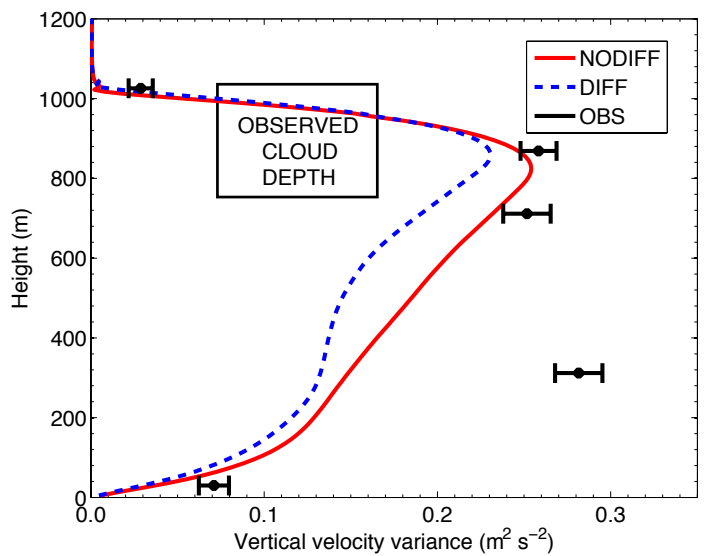

Fig. 2. Comparison of resolved-scale flux profiles between CIRPAS in-situ observations (data points) and LES output (lines). Observations show means (symbol) and computed errors (error bars) over each of the five flight legs. Errors are computed with propagation of measurement uncertainties in Table 2. LES output are domainaveraged and temporally averaged over the sixth hour of simulation. Times of observations and LES output coincide.

diffusion of scalars is neglected. This slight increase is expected; less TKE is used to entrain potentially warmer air and mix it into the boundary layer (i.e. buoyancy destruction of TKE) when the entrainment rate is reduced. As we found in Fig. 2, the agreement between model and observations appears reasonable in-cloud (overestimating by $7 \%$ for DIFF and $25 \%$ for NODIFF at $870 \mathrm{~m}$ ) and poorer for the $300 \mathrm{~m}$ flight leg, underestimating by an order of magnitude in both cases. The observations in Figs. 2 and 3a suggest that parcels of air below cloud are more buoyant and lead to stronger updrafts and downdrafts in this region than what is simulated. Large-eddy simulation has been previously shown to underestimate the strength of STBL circulations when compared to observations (e.g. Stevens et al., 2005).

The two simulations predict similar total water fluxes (Fig. 3b). Each simulation agrees quite well with observed values to within measurement uncertainty, although the observed total water fluxes are subject to substantial uncertainties due to instrument precision. Both simulations exhibit a positive increase in total water flux with height and as the cloud is entered. Total water flux within the STBL is slightly larger for NODIFF because there is more total water within the STBL (Fig. 1b) and because circulations are slightly stronger (Fig. 2).

To determine how well the model can represent the observed variation in cloud LWC, we compared the probability distribution functions (PDF) of LWC as observed on the flight legs near cloud top and mid-cloud to the PDF of LWC in similar layers (Fig. 4). The altitude of the Twin Otter varied by $\sim 25 \mathrm{~m}$ and $\sim 20 \mathrm{~m}$ on the two legs, respectively, and we computed the PDF of LWC with LES output for the same thickness layers.
The PDFs from observations at cloud top exhibits a modal value between 0.42 and $0.43 \mathrm{~g} \mathrm{~kg}^{-1}$ with a long tail towards smaller values of LWC (Fig. 4a). The wide distribution of LWC values observed is due to the Twin Otter traversing both diluted (entrainment of overlying dry air is substantial) and undiluted (entrainment of overlying dry air is small) cloud parcels. At mid-cloud the width of the PDF is narrower (Fig. 4d) because at this height the cloud parcels are turbulently mixed and less entrainment of dry air occurs at this height. The modal value between 0.16 and $0.17 \mathrm{~g} \mathrm{~kg}^{-1}$ is, as expected, lower than at cloud top.

The modeled distributions of LWC at cloud top compare reasonably well with observations. In general the PDFs from LES output (Fig. 4b, c, e, f) are less noisy because there are an order of magnitude more sampling points in the LES than in the flight leg $\left(10^{3}\right.$ in the observations vs. $10^{4}$ in the LES output). The similarity in PDF shape between the model output and observations is strong for DIFF (Fig. 4b). The modal value at cloud top is between 0.35 and $0.36 \mathrm{~g} \mathrm{~kg}^{-1}$, slightly $(16 \%)$ lower than that observed. At cloud top NODIFF (Fig. 4c) results in a modal value between 0.45 and $0.46 \mathrm{~g} \mathrm{~kg}^{-1}$ (neglecting zero LWC values), slightly higher (7\%) than that observed.

The two model predictions of the distribution of LWC mid-cloud both underestimate the modal value. For DIFF (Fig. 4e), the modal value mid-cloud (between 0.11 and $0.12 \mathrm{~g} \mathrm{~kg}^{-1}$ ) underestimates the observations by $30 \%$. The modal value between 0.15 and $0.16 \mathrm{~g} \mathrm{~kg}^{-1}$ for NODIFF (Fig. 4f) is underestimated by $6 \%$ compared to the observations. These differences in model output, paired with the errors at cloud top, suggest differing cloud thicknesses between DIFF and NODIFF. The NODIFF simulation exhibits a thicker cloud layer than that of DIFF (265 m compared to $245 \mathrm{~m}$ ).

It would be preferable to compare observed and simulated LWP. However, because the aircraft sampling strategy focused mainly on horizontal legs it is not possible to generate statistically-significant observational estimates of LWP without assumption. If we assume an adiabatic profile of LWC in a $300 \mathrm{~m}$ thick cloud (as was observed), and set the cloud-top LWC value to the modal observed value, we derive an estimate for LWP in the observed case of $65 \mathrm{~g} \mathrm{~m}^{-2}$. From LES time series output, LWPs averaged over the simulated hour of observation for NODIFF and DIFF are 58.1 and $47.0 \mathrm{~g} \mathrm{~m}^{-2}$, respectively. Thus both simulations appear to underestimate observed LWP (9.9\% and $27.1 \%$, respectively).

The performance of the two LESs in attaining reasonable agreement between model and observations for thermodynamic and flux profiles was comparable. Based on more accurate representation of LWP and circulation strength with respect to observations (shown in Fig. 2), we choose to use NODIFF, in which subgrid diffusion of scalars is neglected, as the base case. Note that our choice does not imply that subgrid, turbulent diffusion is negligible or irrelevant; we simply choose to neglect subgrid diffusion for expediency and 

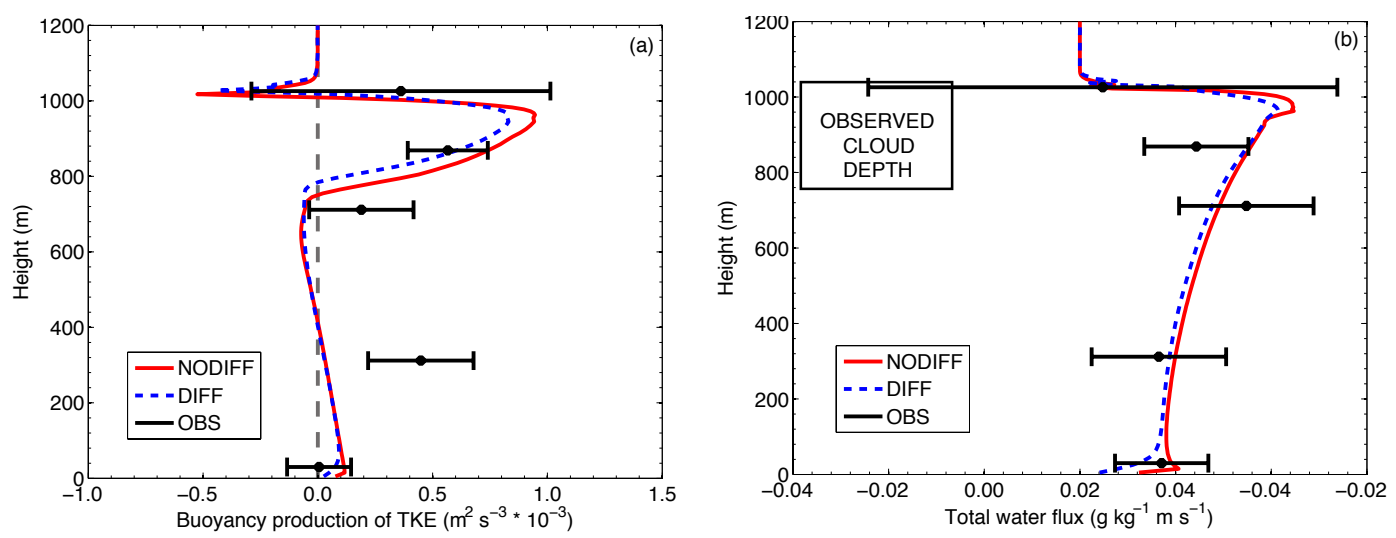

Fig. 3. Comparison of resolved-scale flux profiles between CIRPAS in-situ observations (data points) and LES output (lines). Observations show means (symbol) and computed errors (error bars) over the five flight legs. Errors are computed with propagation of measurement uncertainties in Table 2. LES output are domain-averaged and temporally averaged over the sixth hour of simulation. Times of observations and LES output coincide. The gray dashed line in (a) indicates zero values for visualization.
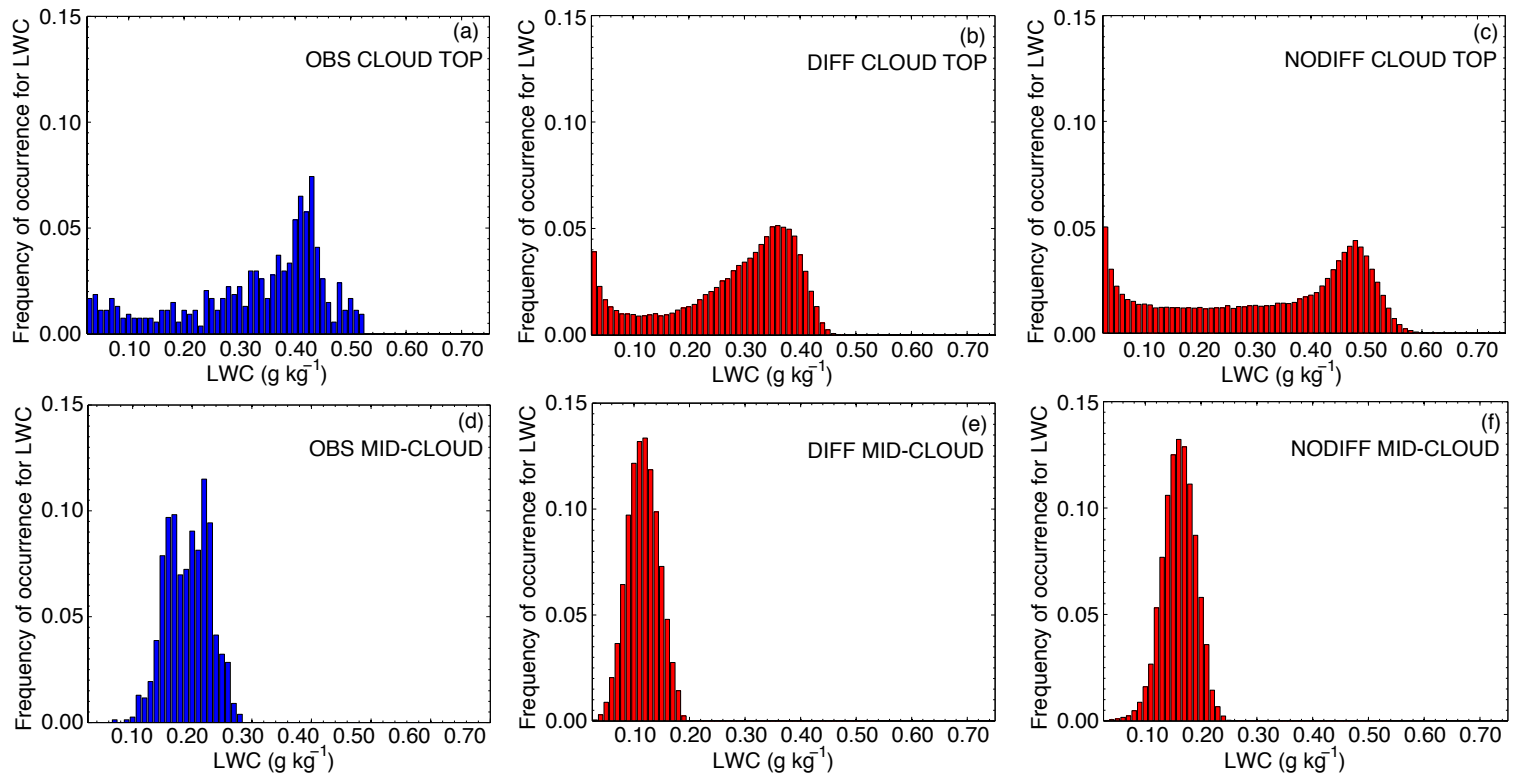

Fig. 4. Probability distribution function (pdf) of liquid water content observed with Phase Doppler Interferometer during flight leg at (a) cloud top, and (d) mid-cloud. These pdfs, as modeled with large-eddy simulation and allowing diffusion of scalars (DIFF) are shown in (b) (cloud top) and (e) (mid-cloud). The same, as modeled while neglecting diffusion of scalars (NODIFF), are shown in (c) (cloud top) and (f) (mid-cloud). Model output from large-eddy simulation is averaged over a $30 \mathrm{~min}$ window centered on time of observation (averaging over 6 snapshots at $5 \mathrm{~min}$ intervals). All liquid water contents are binned into $0.01 \mathrm{~g} \mathrm{~kg}^{-1}$ ranges.

because of the better match between model output and observations.

\section{Experimental design}

\subsection{Determining meteorological and aerosol perturbations}

In creating the experimental simulations for the comparative study, we required that variations in meteorological context have three characteristics: (1) be constrained by observations, (2) be objectively computed, and (3) be determined consistently. In some modeling sensitivity analyses, large perturbations in variables are purposely chosen to maximize the possibility of finding a response. We prefer the perturbations to be more realistic so that the response of the stratocumulus cloud system to one perturbation can be reasonably compared with another.

To determine realistic perturbations in the $q_{\mathrm{t}}$ and $\theta$ jumps for stratocumulus clouds in similar seasons and regions, we 


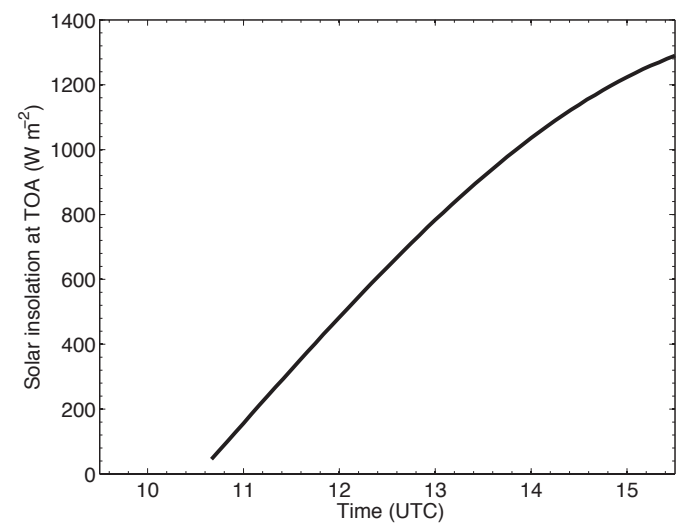

Fig. 5. Solar insolation at TOA as it varies over simulation time for the base case LES. All experimental simulations have the same solar insolation as the base case.

use the ERA-Interim dataset (Uppala et al., 2005, 2008). We chose to use the ERA-Interim data because the ECMWF family of models gives a reasonable match to satelliteobservation monthly mean low cloud fractions in our region of interest (Wyant et al., 2010). We note this match in cloud fractions is somewhat poorer near our region of interest, as are matches in some other properties such as boundary layer depth (Wyant et al., 2010). The ERA-Interim data is also spatially coarse as compared to available observations. However, it give us a far larger temporal variation in meteorology than we would obtain from the observations taken from the Twin Otter during VOCALS (19 flights, 2 soundings taken per flight). This variation is of importance to our study because it helps to expand the applicability of our results to Southeast Pacific coastal stratocumulus outside of those observed during VOCALS. It is prudent to compare our computed perturbations in $q_{\mathrm{t}}$ and $\theta$ jumps to the variations observed from the Twin Otter (Zheng et al., 2011), and we do so below.

We first accumulated daily reanalysis data from the two nearest available reanalysis data points to $20^{\circ} \mathrm{S}, 72^{\circ} \mathrm{W}$, where the Twin Otter conducted all its flights $\left(20.0^{\circ} \mathrm{S}\right.$, $72.4^{\circ} \mathrm{W}$ and $20.0^{\circ} \mathrm{S}, 71.7^{\circ} \mathrm{W}$ ). The data is gridded at $2.5^{\circ}$ by $2.5^{\circ}$ latitude-longitude resolution at six-hour intervals. From the surface $(1000 \mathrm{mb})$ to an altitude of $700 \mathrm{mb}$, the vertical resolution is $25 \mathrm{mb}$. We used all days from September to November from 2001 to 2010 since stratocumulus is persistent during the austral spring in this region. We used 18:00 Z data since this time most closely coincides with the observations.

Although stratocumulus is persistent in the observed region during the austral spring, the stratocumulus layer can be subjected to synoptic changes that influence its robustness (Rahn and Garreaud, 2010). To ensure that a stable stratocumulus layer existed around $20^{\circ} \mathrm{S}, 72.5^{\circ} \mathrm{W}$ for all reanalysis data we excluded data on days when the low cloud fraction was below 0.95 at either of the two reanalysis data points at either 12:00 and 18:00 Z.
To ensure that the reanalysis data exhibit spatial homogeneity around $20^{\circ} \mathrm{S}, 72.5^{\circ} \mathrm{W}$, we also excluded days where the height of the inversion (height of the steepest gradients in temperature and water vapor mixing ratio) did not coincide between the two grid points. Using these strict criteria, we were left with 60 data points from which to compute perturbations.

The ERA-Interim data is of too coarse a vertical resolution $(25 \mathrm{mb})$ to resolve the inversion jump. For this reason we computed the jump properties as the maximum gradient across two $25 \mathrm{mb}$ vertical layers (over $50 \mathrm{mb}$, or roughly $0.5 \mathrm{~km}$ ) between the 1000 and $700 \mathrm{mb}$ levels. With this approach we avoid the $25 \mathrm{mb}$ layer wherein the inversion is represented, and obtain the total change in $\theta$ and $q_{\mathrm{t}}$ across the boundary layer top for our 60 data points.

From this accumulated data set we computed the standard deviation for $\theta$ and $q_{\mathrm{t}}$ jumps across the cloud top interface. Note that the mean values of the jump values within the ERA-Interim data we select do not coincide with the mean values in the model base case. It is the variation of these jumps within the ERA-Interim data that is of interest, and from which we determine the perturbations we use in our modeling framework.

To modify the $q_{\mathrm{t}}$ and $\theta$ jumps above the boundary layer in the experimental simulations, we altered the properties of the model free troposphere instead of the properties of the model boundary layer. We first determined the height of the model boundary layer as the model layer for which the liquid water potential temperature gradient was maximized for each model column in the domain. We then modified the instantaneous values of $q_{\mathrm{v}}$ or $\theta$ for all model layers above the boundary layer.

For the simulations where the $\theta$ jump was modified, we increased and decreased the $\theta$ above the boundary layer by one standard deviation (UP THETA and DOWN THETA, $\pm 1.3 \mathrm{~K})$. Because the observed free tropospheric $q_{\mathrm{v}}$ is low (below $1.0 \mathrm{~g} \mathrm{~kg}^{-1}$ ), the two perturbations for the $q_{\mathrm{t}}$ jump were both in the positive direction; by one standard deviation (UP MOIST, $+0.87 \mathrm{~g} \mathrm{~kg}^{-1}$ ) and by two standard deviations (UP 2XMOIST, $+1.74 \mathrm{~g} \mathrm{~kg}^{-1}$ ).

We compared our computed perturbations in $q_{\mathrm{t}}$ and $\theta$ jump to the variations in these jumps observed from the Twin Otter (see Zheng et al., 2011, Table 2). Our computed jump in $\theta$ is smaller by $0.7 \mathrm{~K}( \pm 1.9 \mathrm{~K}$ observed), while our computed jump in $q_{\mathrm{t}}$ smaller by more than a factor of two $\left( \pm 2.2 \mathrm{~g} \mathrm{~kg}^{-1}\right.$ observed). The ERA-Interim data may not capture the free tropospheric variability observed from the Twin Otter during VOCALS. Our possible underestimation of the magnitude of $q_{\mathrm{t}}$ and $\theta$ variabilities could lead to underestimation of the associated cloud response.

We would prefer that the perturbations in meteorological context and aerosol state originate from the same dataset and using the same methodology. Aerosol and cloud droplet data are not available in the ERA-Interim dataset, however. Therefore we must use a different methodology to get a "1-sigma" 
Table 4. Aerosol and meteorological properties varied and for which the response of cloud properties LWP, optical depth and cloud radiative forcing are computed.

\begin{tabular}{|c|c|c|c|}
\hline Factor & Modify by & Possible impacts on STBL & References \\
\hline Potential temperature jump & $\begin{array}{l}\text { Increase/decrease potential } \\
\text { temperature above } \mathrm{BL} \text { by } 1.3 \mathrm{~K}\end{array}$ & $\begin{array}{l}\text { Modulates energy } \\
\text { transfer through and amount of } \\
\text { entrainment mixing }\end{array}$ & Lilly (1968); Sullivan et al. (1998) \\
\hline
\end{tabular}

variation in aerosol state, acknowledging that rigorous correspondence does not exist between our meteorological and aerosol perturbations.

We chose to perturb only total aerosol concentration $N_{\mathrm{a}}$, with no change in the mean particle size $\bar{D}_{\mathrm{p}}(0.12 \mu \mathrm{m})$. The simulated change in cloud drop concentration correlates strongly with the aerosol concentration perturbations. The initial mean values of model $N_{\mathrm{a}}$ and $N_{\mathrm{d}}$ in the base case $\left(N_{\mathrm{a}}=450 \mathrm{~cm}^{-3}, N_{\mathrm{d}}=425 \mathrm{~cm}^{-3}\right)$ represent a strongly polluted stratocumulus case with substantial activation of aerosol. As a result, we elected not to impose an increase in aerosol concentration as a perturbation. Instead, we maintain the same aerosol size distribution shape and decrease the aerosol concentration by factors of 2 and 4 , thereby simulating moderately polluted (HALF ND) and fairly clean (QUARTER ND) STBL cases, respectively. The lowest values of $N_{\mathrm{a}}=113 \mathrm{~cm}^{-3}, N_{\mathrm{d}}=106 \mathrm{~cm}^{-3}$ are fairly representative of the clean STBL (Miles et al., 2000).

In order to span the full range of aerosol and cloud droplet concentrations observable within stratocumulus, a lower-end value of $N_{\mathrm{d}}=50 \mathrm{~cm}^{-3}$ is probably more appropriate, while the upper range $N_{\mathrm{d}}=425 \mathrm{~cm}^{-3}$ is a reasonable upper value. Although we do not have decadal time series of aerosol data available for the region of interest, we note that the Twin Otter observed $N_{\mathrm{d}}$ to vary between $80 \mathrm{~cm}^{-3}$ and $400 \mathrm{~cm}^{-3}$ during VOCALS (Zheng et al., 2011). Thus our selected $N_{\mathrm{d}}$ range is reasonable compared to the available observations.

The aerosol and meteorological properties that are varied, the magnitude of these variations, and possible ways in which the cloud will respond to these variations, are summarized in Table 4. We focused on the response of stratocumulus to those meteorological factors likely to modify STBL evolution on time scales less than a day.

\subsection{Configuration of experimental simulations}

By perturbing the base simulation with one perturbation at a time from Table 4 (two different perturbations of one aerosol and each of two meteorological properties), we created six separate experimental simulations. The perturbations described in the previous subsection were added at 09:30 UTC, two hours into the base LES, and the simula- tions were allowed to run for an additional six hours, to 15:30 UTC. At this time the cloud layer begins to break up. Simulating this time period allows us to determine how the responses of LWP, $\tau$ and CRF for overcast stratocumulus vary through the observation period to near solar noon. For reference, Fig. 5 shows the temporal variation of solar insolation at TOA for the base simulation.

As noted above, meteorological context and aerosol state are often correlated (Brenguier et al., 2003). Independent meteorological variables are also often correlated with each other. Here we assume independence because attributing changes in cloud properties $\Delta c$ to changes in specific aerosol and meteorological factors will be simpler if we only consider factors one at a time. Interactions between two or more co-varying properties would make the attribution process more difficult. Examining changes in the cloud response to co-varying aerosol and meteorological properties is left to future study, possibly using the factorial method (Teller and Levin, 2008).

\section{Results from experimental simulations}

We first briefly describe the time evolution of the cloud layer in the model base case to provide some context for the discussion of the perturbation simulations. From 09:30 UTC to 15:30 UTC, the base case LWP decreases from $67 \mathrm{~g} \mathrm{~m}^{-2}$ to $18 \mathrm{~g} \mathrm{~m}^{-2}$ as solar insolation increases. After 14:00 UTC the cloud layer has thinned such that it is optically thin in the longwave (LW) (Garrett and Zhao, 2006; Petters et al., 2012), and LW radiative cooling from the cloud top begins to decrease slightly with time.

Cloud fraction, defined as the ratio of model columns with $\mathrm{LWP}<10 \mathrm{~g} \mathrm{~m}^{-2}$ to the total number of model columns, departs from unity shortly after 14:00 UTC and decreases to $\sim 0.9$ by $15: 30$ UTC when we end the base simulation (see Fig. 8e). The boundary layer deepens over the six hours, reaching a nearly steady height at the end of simulation. This deepening indicates that entrainment of the overlying dry air cloud also play a role in the decrease in LWP. We again note that the base simulation is of non-drizzling stratocumulus; drizzle does not play a measurable role in any 

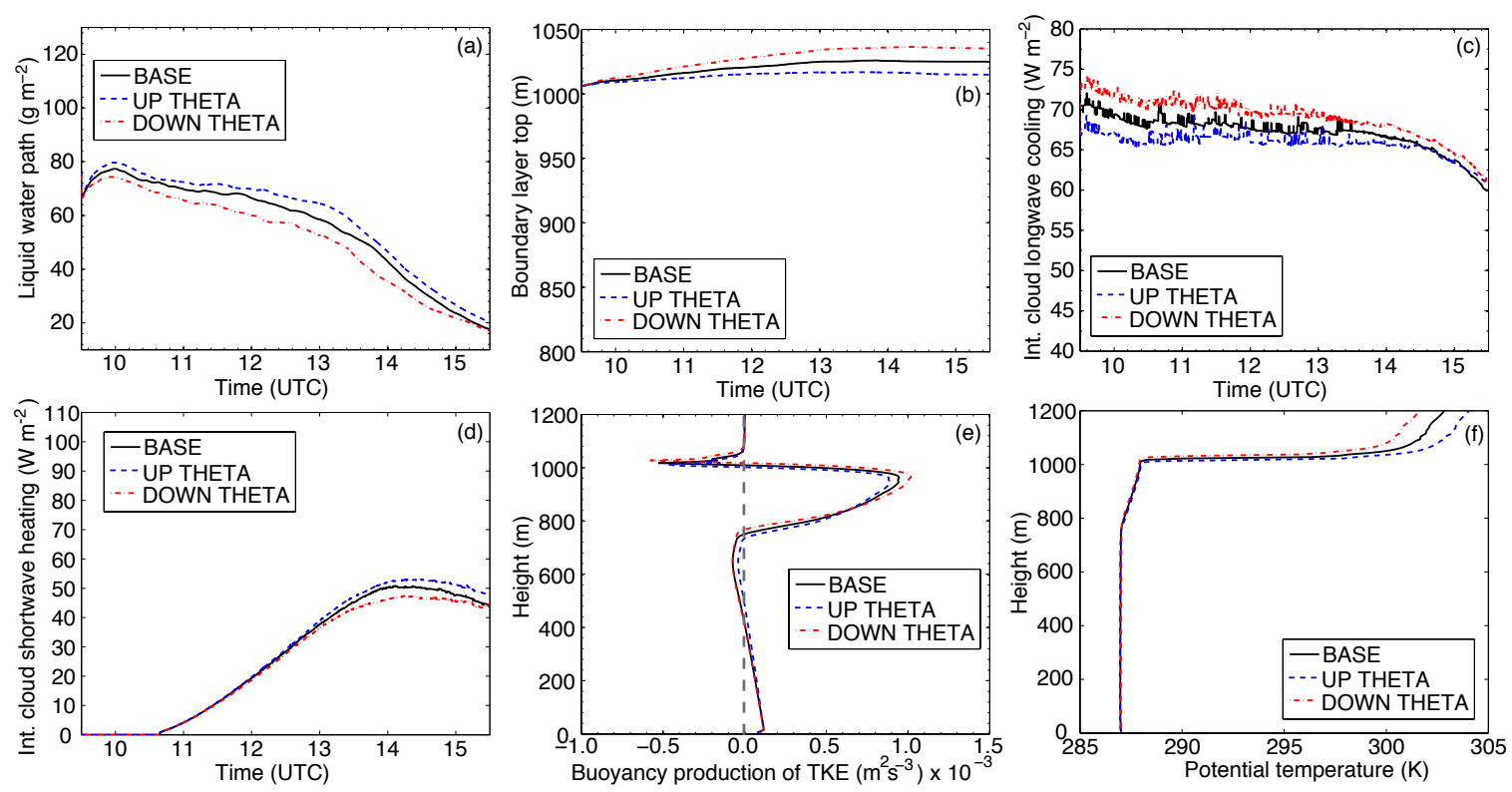

Fig. 6. LES output showing STBL response for changes in potential temperature jump across the cloud top interface. Time series of quantities, shown in (a) to (d), are domain averaged and vertically integrated. Vertical profiles, shown in (e) and (f), are domain averaged and temporally averaged over the hour of observation (12:30 to 13:30 UTC).

of the experimental simulations, even in those where cloud droplet concentrations were reduced.

\subsection{Response to perturbations in potential temperature jump}

Perturbations in the $\theta$ jump from the base case (labeled BASE) lead to changes in entrainment rate that affect cloud LWP. Together Fig. 6a, $\mathrm{f}$ show that an increase in the $\theta$ above the STBL leads to a higher LWP and vice versa (simulations UP THETA and DOWN THETA, respectively).

As suggested by other studies (e.g. Lewellen and Lewellen, 1998; Sullivan et al., 1998; Sun and Wang, 2008), an increase in the $\theta$ jump leads to stronger stability (i.e. greater density contrast) across the interface, reducing the rate at which dry air from above the cloud top entrains into the boundary layer. Also, because of the increase in $\theta$ above the boundary layer, cloud integrated LW radiative cooling is reduced (Fig. 6c) and hence there is less buoyant production of TKE within the cloud layer (Fig. 6e). Buoyant production is the primary source of TKE within the convective STBL, and a decrease in this quantity results in less TKE available to drive entrainment. Taken together, these two mechanisms lead to a slower increase in boundary layer height (Fig. 6b). Boundary layer height is directly related to entrainment rate because large-scale subsidence is the same in all simulations (see Table 1).

The converse of these qualitative arguments applies when the $\theta$ jump is decreased. However, the cloud response is not identical in magnitude for the positive and negative $\theta$ jumps, i.e. the response is not symmetric.
As the sun rises toward mid-day and cloud integrated SW radiative heating increases (Fig. 6d), LWP decreases in all three simulations. Shortwave radiative heating increases with LWP and explains in part why the LWP for the UP THETA simulation decreases more rapidly after 13:00 UTC as compared to the other two. Integrated LW cooling also decreases after 13:00 UTC in all three simulations as the cloud layer becomes optically thin in that portion of the electromagnetic spectrum.

\subsection{Response to perturbations in moisture jump}

For the base case, decreases in the magnitude of the $q_{\mathrm{t}}$ jump (i.e. moistening the free troposphere) lead to increases in LWP (Fig. 7a, f). Like the STBL response to changes in the $\theta$ jump, changes in LWP are related to changes in the entrainment process and the magnitude of LW radiative cooling. For the same amount of entrained overlying air into the STBL, increasing $q_{\mathrm{v}}$ above the boundary layer leads to less evaporation of cloud and less associated evaporative cooling. This change in the entrainment process partly explains both the increase in LWP with increasing free tropospheric $q_{\mathrm{t}}$, as well as the increase in latent heating at cloud top (Fig. 7d). Simultaneously, integrated LW radiative cooling decreases as there is more water vapor to emit LW radiation to the top of the cloud (Fig. 7c).

As in Fig. 6, this decrease in integrated LW cooling (in conjunction with less cloud top evaporative cooling) leads to less buoyancy production of TKE (Fig. 7e) when the magnitude of the $q_{\mathrm{t}}$ jump decreases. Again, as this incloud buoyancy production decreases, we find a reduction in 

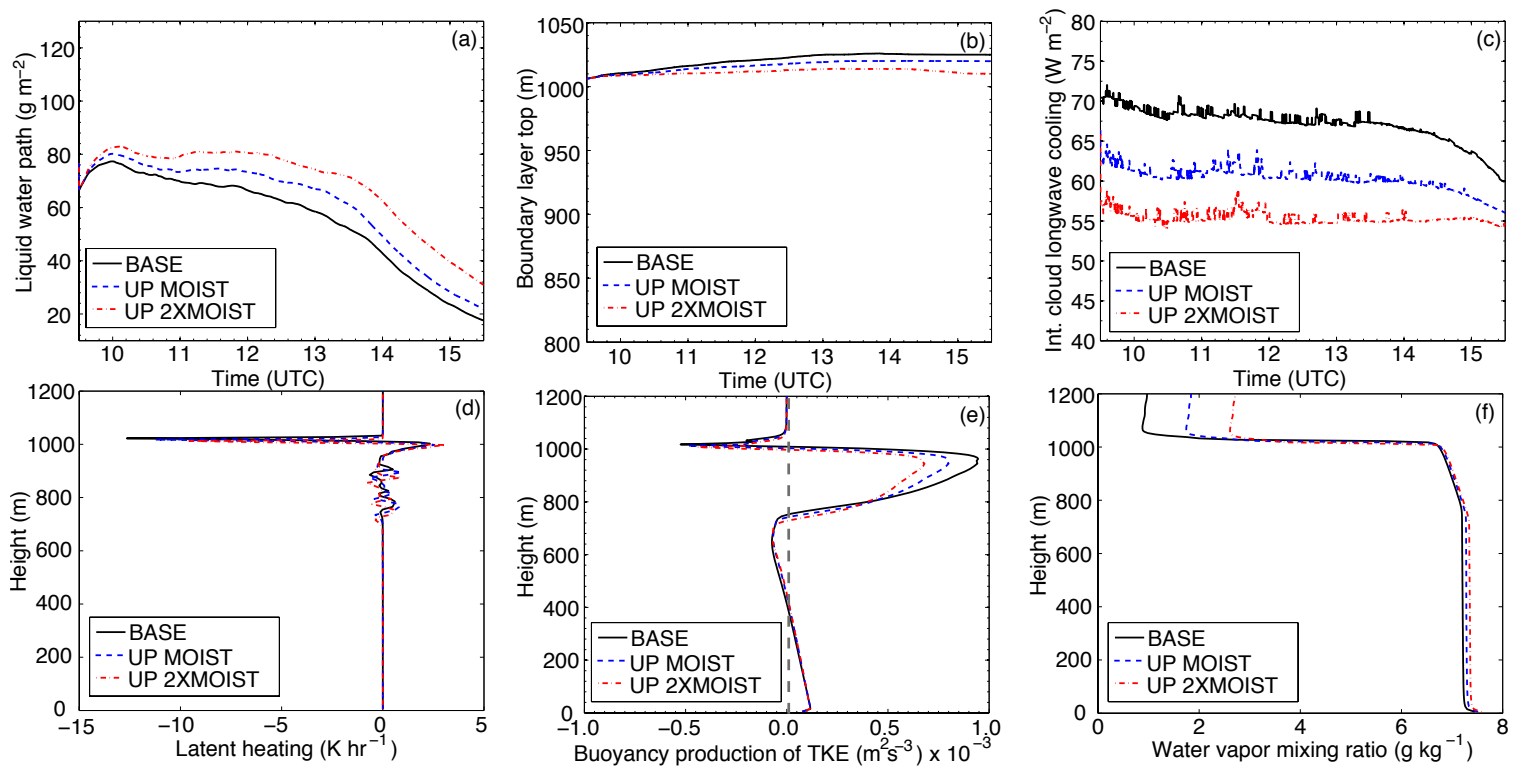

Fig. 7. LES output showing STBL response for changes in moisture jump across the cloud top interface. Time series of quantities, shown in (a) to (c), are domain averaged and vertically integrated. Vertical profiles, shown in (d) to (f), are domain averaged and temporally averaged over the hour of observation (12:30 to 13:30 UTC).

entrainment rate, which can be seen as a reduction in boundary layer growth (Fig. 7b). This reduction in entrainment rate with increased free tropospheric $q_{\mathrm{t}}$ also leads to less evaporation of cloud. There is less mixing of relatively dry overlying air into the cloud, and what mixing does occur brings in moister cloud-free air.

Different from the perturbations in $\theta$ jump, one of the simulations, UP 2XMOIST, does not appear to become optically thin in the LW spectrum near the end of simulation. Integrated LW radiative cooling decreases only slightly at the end of simulation, whereas for the other two (BASE and UP MOIST) LW cooling decreases more substantially (Fig. 7c). Furthermore, comparing Fig. 6a to Fig. 7a shows that the response of LWP to the moisture jump perturbations is larger than the response to $\theta$ jump perturbations. This difference in LWP response has important bearing on the associated response of $\tau$ and CRF.

\subsection{Response to perturbations in aerosol concentration}

Previous studies have shown that perturbations in $N_{\mathrm{a}}$ and $N_{\mathrm{d}}$ can lead to either cloud thinning or thickening. When large scale forcings such as subsidence and SW forcing are held constant, changes in either the drizzle process (Albrecht, 1989; Jiang et al., 2002) or the entrainment process (Ackerman et al., 2004; Bretherton et al., 2007; Hill et al., 2009) can each play important roles in the STBL response. We found that, compared to our descriptions of cloud response to the meteorological perturbations, accurate description of how perturbations to $N_{\mathrm{a}}$ and $N_{\mathrm{d}}$ impact the simulations requires more elaboration.
Relative to the base case, decreases in $N_{\mathrm{a}}$ and $N_{\mathrm{d}}$ lead to increases in LWP (Fig. 8a). Increases in LWP with decreases in $N_{\mathrm{a}}$ and $N_{\mathrm{d}}$ occur almost immediately after the aerosol perturbations were introduced at 09:30 UTC. What is the mechanism causing the immediate divergence in model LWPs with changes in $N_{\mathrm{a}}$ and $N_{\mathrm{d}}$ ? Because the thermodynamic profiles of all three simulations are identical immediately after the aerosol perturbations are introduced, it is unlikely that thermodynamics play a role in the immediate response (though feedbacks to the thermodynamic state could strongly affect the longer time-scale response). Instead we look to immediate changes in microphysical processes when cloud droplet concentration is altered (Fig. 9).

Our simulations exhibit a weak drizzle process. Even when $N_{\mathrm{d}}$ is decreased to its lowest value in QUARTER ND there is negligible sedimentation of cloud water below cloud base (not shown). Thus we look to potential changes in the entrainment process. When cloud droplet concentration is decreased evaporative cooling at cloud top is expected to decrease for two reasons: there is less total droplet surface area through which liquid water can become water vapor (Wang et al., 2003; Ackerman et al., 2004; Hill et al., 2009), and there are fewer droplets near the cloud top interface because larger droplets sediment faster (Bretherton et al., 2007; Hill et al., 2009).

As the evaporation rate near cloud top decreases, LWP would be expected to increase. We see that, for the first half hour after perturbations are induced, evaporative cooling (negative latent heating) at cloud top (associated with entrainment) does decrease with decreases in $N_{\mathrm{a}}$ and $N_{\mathrm{d}}$ (Fig. 9a). Thus these changes in evaporation at cloud top can 

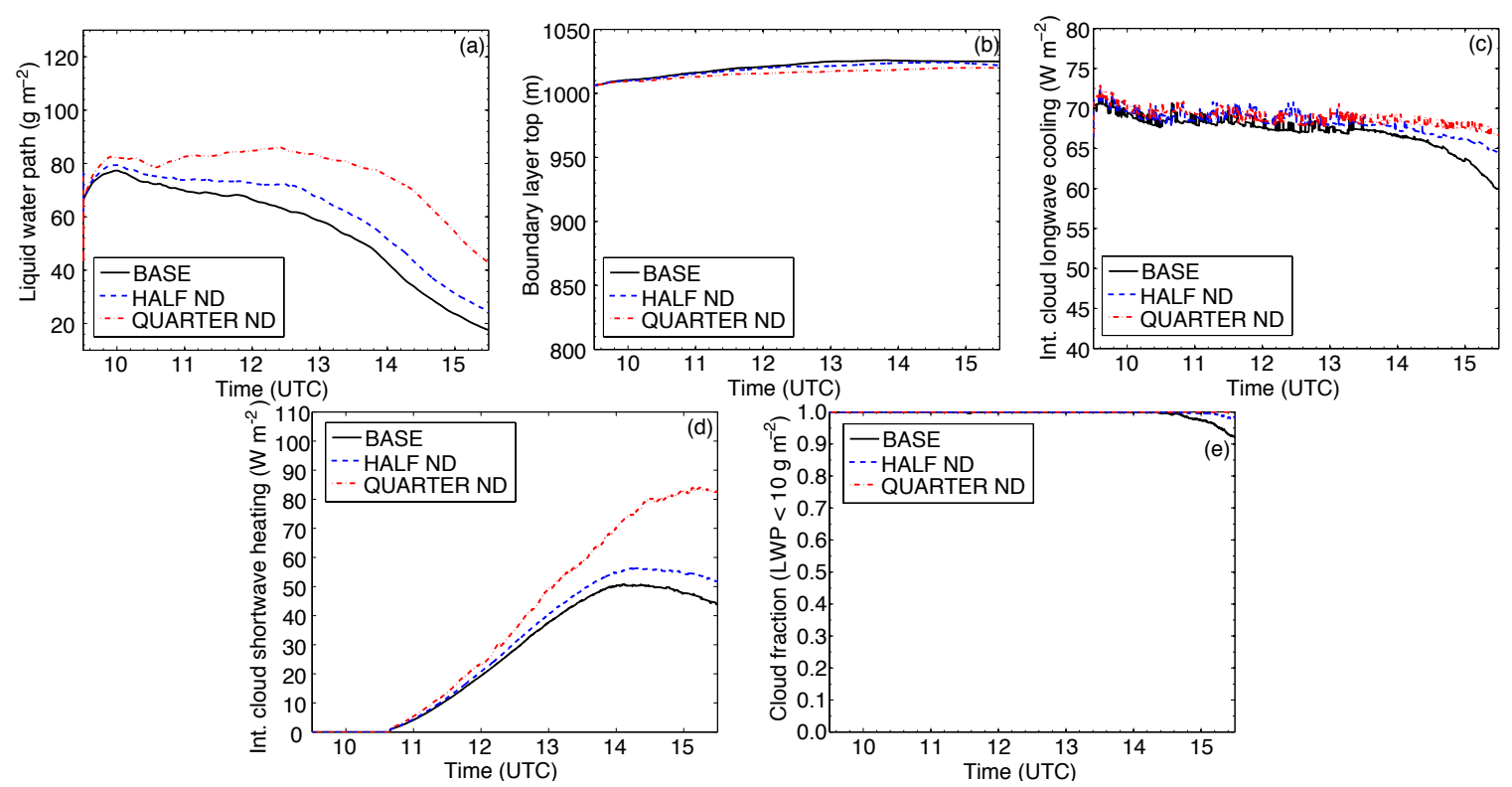

Fig. 8. LES output showing STBL response for changes in aerosol and cloud droplet concentrations. Domain averaged and vertically integrated time series of quantities are shown.
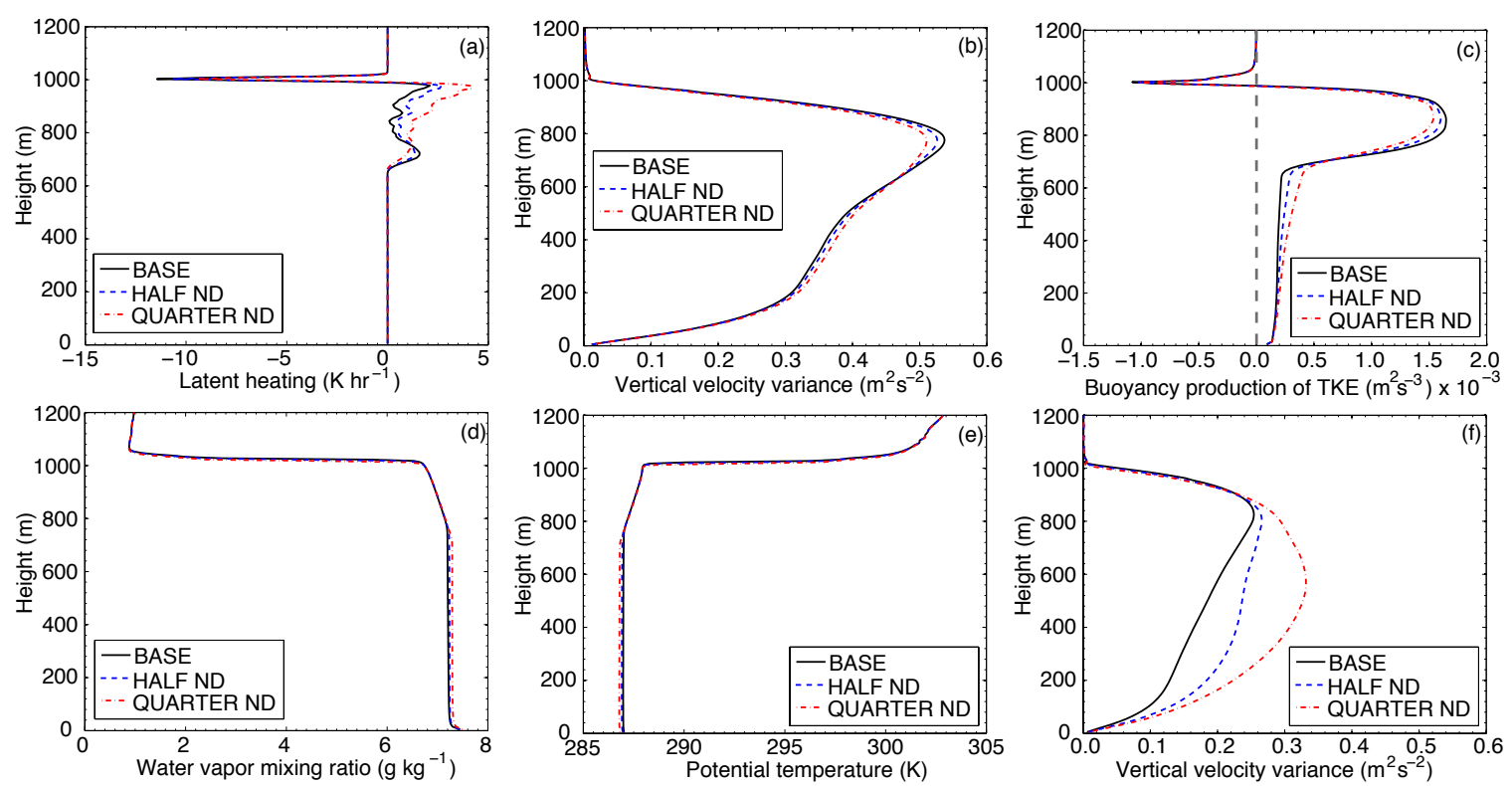

Fig. 9. LES output showing STBL response for changes in aerosol and cloud droplet concentrations. Vertical profiles, shown in (a) to (c), are domain averaged and temporally averaged over the first fifteen minutes of simulation after perturbation (09:30 to 09:45 UTC). Vertical profiles, shown in (d) to (f), are domain averaged and temporally averaged over the hour of observation (12:30 to 13:30 UTC).

be related to the increases in LWP seen in Fig. 8a immediately after 09:30 UTC.

Less evaporative cooling at cloud top also causes less buoyancy production of TKE in that region (Fig. 9c), resulting in decreases in $\overline{w^{\prime} w^{\prime}}$ near cloud top (Fig. 9b, around $800 \mathrm{~m}$ altitude). Weaker turbulence leads to less vigorous entrainment, and thereby larger LWP can be maintained. As a whole this process is known as the evaporation-entrainment effect (Hill et al., 2009). This effect could also play a role in the immediate increases in LWP with decreased $N_{\mathrm{d}}$ at 09:30 UTC.

We note our model vertical resolution of $5 \mathrm{~m}$ is unable to explicitly resolve mixing across the stratocumulus cloud top interface (Stevens et al., 2005). Even with subgrid fluxes turned off, spurious diffusion of cloud droplets across the interface can occur within LES, leading to an overestimation 


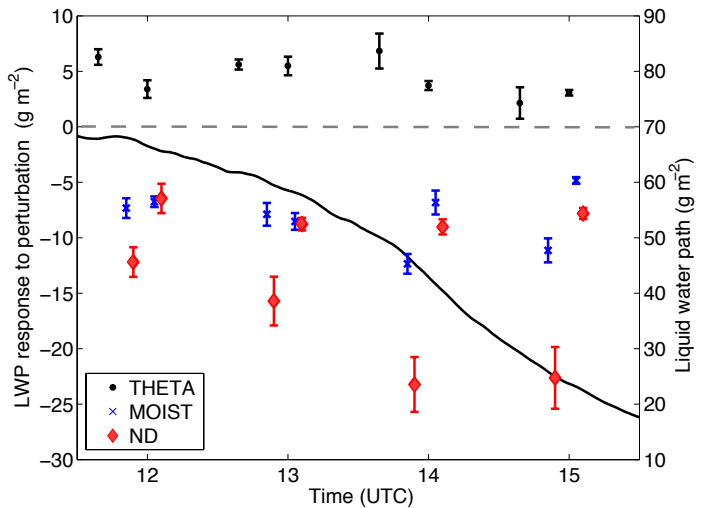

Fig. 10. Response of LWP to perturbations in meteorological context and aerosol state, computed from the experimental simulations (left y-axis). All mean responses are computed using 5-min temporally and domain averaged data, averaged over each of the four hours. Standard deviations for these means are shown with error bars. The grey dashed line indicates a zero response in LWP. The hour over which we average is the same for each computed response; we spread the responses out around each time for clarity. There are two computed hourly responses for each perturbation type; refer to Table 5 for exact expressions. For reference the black line shows the time series of base case LWP (right y-axis).

of entrainment efficiency (Bretherton et al., 1999). We anticipate this overestimation to somewhat exaggerate the strength of cloud top evaporation and its dependence on $N_{\mathrm{a}}$ and $N_{\mathrm{d}}$.

We also find that, in response to the evaporationentrainment effect, boundary layer growth decreases with decreases in $N_{\mathrm{d}}$ (Fig. 8b) as entrainment rate decreases. This change in boundary layer growth plays an important role in the further evolution of these simulations. Before we elaborate further, we first consider the impacts of LW radiative cooling and SW radiative heating.

Figure 8c shows us that integrated LW cooling is similar across all three simulations until about 13:30 UTC. After 13:30 UTC we see that LW cooling is dependent on $N_{\mathrm{d}}$ due to variations in cloud thinning and reductions in cloud fraction with $N_{\mathrm{d}}$ (Fig. 8e). After this time, as $N_{\mathrm{d}}$ decreases, integrated LW cooling increases because the cloud fraction increases and individual cloudy model columns are more likely to be optically thick in the LW. This change in LW cooling with $N_{\mathrm{d}}$ could help explain the slight increase in differences in LWP across the three simulations after 13:30 UTC; more LW cooling within the boundary layer can lead to cloud growth through a lowering of the lifting condensation level.

Decreases in $N_{\mathrm{d}}$ lead to more integrated SW heating (Fig. 8d). Because cloud integrated SW heating increases with increases in both LWP and $N_{\mathrm{d}}$, it is clear that the increase in LWP and consequent increase in cloud SW heating dominates the expected decrease in SW heating due to decreases in $N_{\mathrm{d}}$. If SW heating were to play a primary role, we would expect LWP values across the simulations to become more similar during the day because higher LWP val-

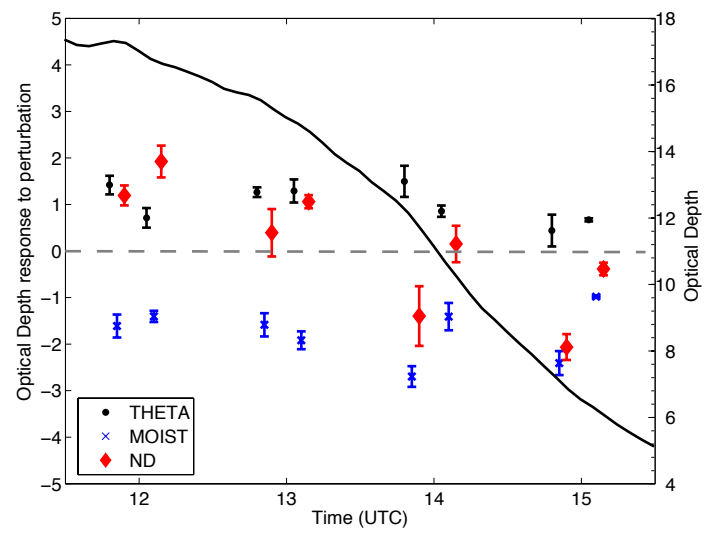

Fig. 11. Response of optical depth $(\tau)$ to perturbations in meteorological context and aerosol state, computed from the experimental simulations (left y-axis). Responses of $\tau$ are shown as described in Fig. 11. For reference the black line shows the time series of base case $\tau$ (right $\mathrm{y}$-axis) and the grey dashed line indicates a zero response in $\tau$.

ues beget more heating and would lead to more cloud evaporation. Because we do not find this relationship between LWP and $N_{\mathrm{d}}$ (Fig. 8a), we turn to the role of boundary layer growth and entrainment to explain the simulated longer-term response to aerosol.

Averaged over the fourth hour of simulation after the perturbations were induced (12:30 to 13:30 UTC), $q_{\mathrm{v}}$ and $\theta$ profiles indicate that, as $N_{\mathrm{d}}$ decreases, a cooler, moister STBL results (Fig. 9d, e) that leads to more cloud growth. This cooler, moister STBL can be attributed to slower boundary layer growth and entrainment (Fig. 8b); more entrainment of warm, dry overlying air leads to a warmer, drier STBL. Note that Fig. 9d and e are qualitatively representative of adjacent hourly periods for these simulations.

Although the differences are small, we see near cloud top $(900 \mathrm{~m}$ to $1000 \mathrm{~m}$ ) for the hour between $12: 30$ and 13:30 UTC that $\overline{w^{\prime} w^{\prime}}$ is smaller for the lower values of $N_{\mathrm{d}}$ (Fig. 9f). This relationship can again be associated with the evaporation-entrainment feedback, as we found near cloud top from 09:30 UTC to 09:45 UTC (Fig. 9b). This relationship between circulation strength and $N_{\mathrm{d}}$ near cloud top is in contrast with the more obvious increase of $\overline{w^{\prime} w^{\prime}}$ with decreases in $N_{\mathrm{d}}$ for the bulk of the STBL. However, we must keep in mind the importance of circulation strength near cloud top in determining entrainment rate, as opposed to circulation strength through the boundary layer (Lilly, 2002; Caldwell and Bretherton, 2009). Taken as a whole, and as seen in Wang et al. (2003), Figs. 8 and 9 show that decreases in evaporative cooling and entrainment rate with decreases in $N_{\mathrm{a}}$ and $N_{\mathrm{d}}$ result in the increases of LWP found in this set of simulations. 
Table 5. Expressions depicting how the two hourly-averaged responses (leftmost and rightmost for each hour) are computed for each perturbation in Fig. 10 to 13. The expressions in the rightmost column use the simulation names described in Sect. 5.

\begin{tabular}{lll}
\hline Perturbation & Left-hand & Right-hand \\
\hline Aerosol concentration & (HALF ND)-(QUARTER ND) & (BASE)-(HALF ND) \\
Moisture jump & (UP MOIST)-(UP 2XMOIST) & (BASE)-(UP MOIST) \\
Potential temperature jump & (BASE)-(DN THETA) & (UP THETA)-(BASE) \\
\hline
\end{tabular}
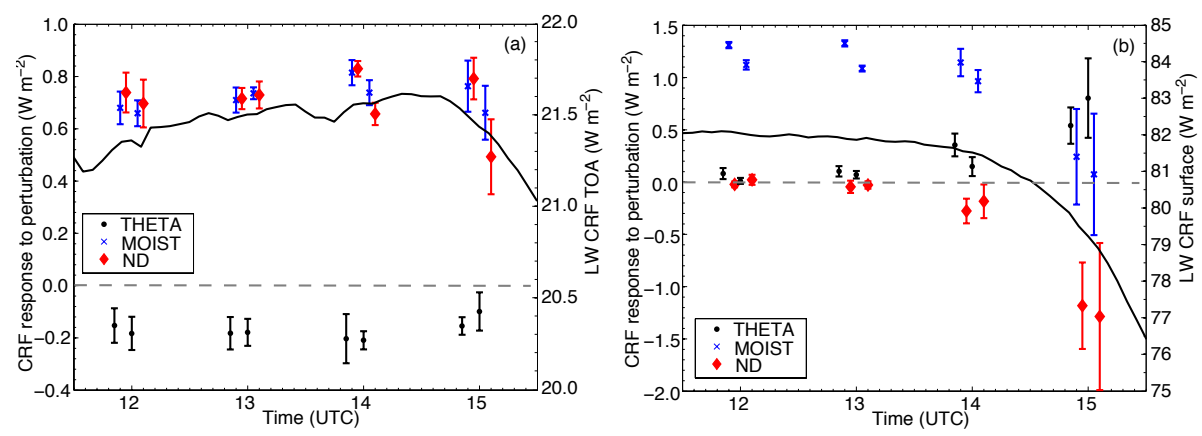

Fig. 12. Response of longwave cloud radiative forcing (LW CRF), at (a) TOA and (b) the surface to perturbations in meteorological context and aerosol state, computed from the experimental simulations (left y-axis). Responses of LW CRF are shown are shown as described in Fig. 11. For reference the black line shows the time series of base case LW CRF (right y-axis) and the grey dashed line indicates a zero response in LW CRF.

\section{The computed response in cloud properties}

To objectively compare the impact of the perturbations in meteorological context $\Delta m$ and aerosol state $\Delta a$ on the model base case, we computed the response of three cloud properties $\Delta c$ (LWP, $\tau$ and CRF) to these perturbations. We computed these responses from 5-min domain averaged cloud properties, averaged over one hour centered on each of the last four hours of simulation (12:00, 13:00, 14:00 and 15:00 UTC).

Because we have two separate perturbations (e.g. UP THETA and DOWN THETA) for each of the three perturbed parameters, we computed two hourly-averaged cloud responses for each hour.

For all perturbation types, the two responses are reported by comparing cloud properties for (i) the simulations using the middle (absolute) value of $\theta$ jump, $q_{\mathrm{t}}$ jump, and $N_{\mathrm{a}}$ and $N_{\mathrm{d}}$ relative to the simulation using smallest value, and then (ii) by comparing the simulations using the largest perturbed parameter value relative to the middle value. See Table 5 for the exact choice of simulations used for each response calculation.

Figures 10 to 13 show these computed responses. While the hour over which we average is the same for all responses, we slightly shift the results left or right at each hour for clarity. As shown in Table 5, at each hour in Figs. 10 to 13 the point slightly shifted to the left is for the middle-smallest simulations, while the point shifted to the right is for the largest-middle simulations.

\subsection{The response to changes in jump properties compared to the response to changes in droplet concentration}

\subsubsection{Liquid water path}

Figure 10 shows the time evolution of the response of LWP. Averaged over the two responses at each hour and across all four hours, the LWP response to increases in $N_{\mathrm{d}}$ is the largest in magnitude $\left(-13 \mathrm{~g} \mathrm{~m}^{-2}\right)$, followed by the response to increases in the $q_{\mathrm{t}}$ jump $\left(-8 \mathrm{~g} \mathrm{~m}^{-2}\right)$. The average LWP response to increases in the $\theta$ jump is the smallest at $5 \mathrm{~g} \mathrm{~m}^{-2}$.

For each perturbation, the LWP response varies with hour and, in some cases, at each hour between the two perturbations (e.g. UP THETA and DOWN THETA). The LWP response to increases in the $\theta$ jump is positive and varies the least over simulation time (between 2 and $7 \mathrm{~g} \mathrm{~m}^{-2}$ ). The LWP response to increases in the $q_{\mathrm{t}}$ jump (decrease in free tropospheric $q_{\mathrm{t}}$ is negative, varying between -5 and $-12 \mathrm{~g} \mathrm{~m}^{-2}$. Within each hourly average, the LWP response to changes in $\theta$ jump is fairly linear (e.g. the response at each hour for UP THETA and DOWN THETA are similar). For changes in the $q_{\mathrm{t}}$ jump, the LWP response is fairly linear at 12:00 and 13:00 UTC and less so at 14:00 and 15:00 UTC.

The LWP response to increases in $N_{\mathrm{d}}$ is negative and varies between -6 and $-23 \mathrm{gm}^{-2}$. For all four hours we find a non-linear LWP response to these increases in $N_{\mathrm{d}}$. The first increase from $N_{\mathrm{d}}=106 \mathrm{~cm}^{-3}$ to $N_{\mathrm{d}}=213 \mathrm{~cm}^{-3}$ yields the larger response in LWP, and is associated with non-linear 

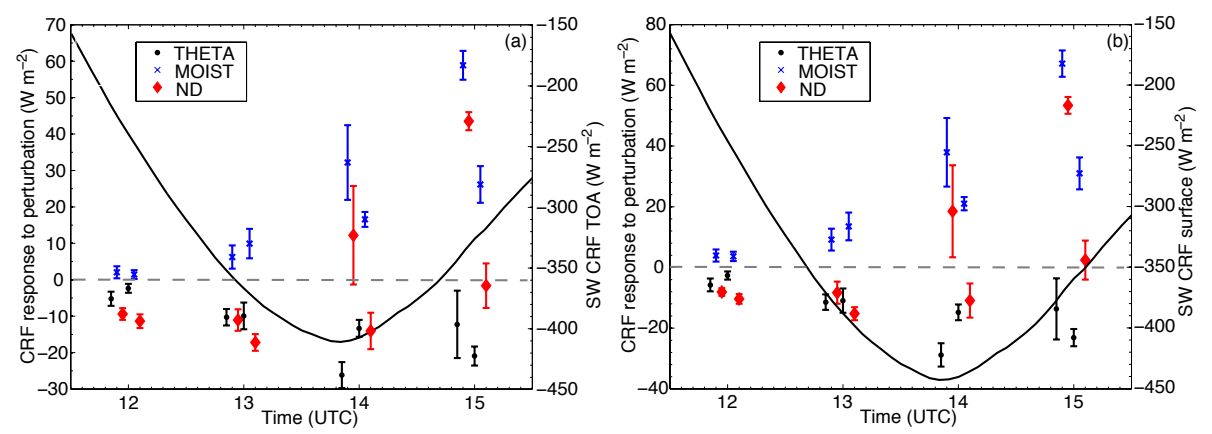

Fig. 13. Response of shortwave cloud radiative forcing (SW CRF), at (a) TOA and (b) the surface to perturbations in meteorological context and aerosol state, computed from the experimental simulations (left y-axis). Responses of SW CRF are shown as described in Fig. 11. For reference the black line shows the time series of base case SW CRF (right y-axis) and the grey dashed line indicates a zero response in SW CRF.

changes in entrainment rate with $N_{\mathrm{d}}$ (Fig. 8b). This nonlinearity increases with time.

Because of the substantial decrease in LWP during the day, relative LWP response varies more widely with time as compared to absolute LWP responses. For example, relative LWP responses to increases in $N_{\mathrm{d}}$ vary from $-10 \%$ at 12:00 UTC to $-94 \%$ at 15:00 UTC, when the cloud layer is thinnest.

\subsubsection{Optical depth}

We found the LWP response to changes in meteorological perturbations $(\Delta m)$ to be of the same magnitude, or smaller, than the LWP response to aerosol perturbations $(\Delta a)$ (Fig. 10). However, the LWP response to these perturbations can not be directly translated into radiative responses. In general bulk optical depth $\tau$ is proportional to LWP, $N_{\mathrm{d}}$ and the dispersion of the cloud drop size distribution, represented by $k$ (Brenguier and Geoffroy, 2011):

$\tau \sim\left(k N_{\mathrm{d}}\right)^{1 / 3} \mathrm{LWP}^{5 / 6}$.

We computed $\tau$ for the SW portion of the spectrum using:

$\tau=\int_{z_{\mathrm{b}}}^{z_{\mathrm{t}}} \int_{r_{1}}^{r_{\mathrm{u}}} 2 \pi r^{2} n(r) \mathrm{d} r \mathrm{~d} z$,

where $z_{\mathrm{t}}$ and $z_{\mathrm{b}}$ are the heights of the cloud top and cloud base, respectively, $r_{\mathrm{u}}$ and $r_{\mathrm{l}}$ are the radius size range of the drop size distribution and $n(r)$ is the number of drops between $r$ and $r+\mathrm{d} r$ (Seinfeld and Pandis, 1998). The extinction efficiency is assumed to be 2. Using output of 5-min averaged cloud droplet size distribution data, we integrated the model drop size distribution first over the 25 bins in the microphysical model and then over the total depth of the cloud layer. For the base case, changes in $\tau$ with time follows the same trend as LWP with time (compare the black lines on Fig. 10 and Fig. 11), as expected from Eq. (1).

The optical depth response to perturbations in the two jump properties is proportional to LWP responses (Fig. 11).
For increases in $q_{\mathrm{t}}$ jump strength, hourly-averaged values of this response in $\tau$ are between $-2.7(-25 \%)$ to -1.0 $(-15 \%)$. For increases in $\theta$ jump strength, hourly-averaged values of $\tau$ increase by $0.7(11 \%)$ to $1.5(8 \%)$. Note that relative response in $\tau$ is computed relative to their corresponding "BASE" hourly-averaged $\tau$ values.

Comparison of the response in $\tau$ to $N_{\mathrm{d}}$ perturbations (Fig. 11) to the concurrent response in LWP (Fig. 10) reveal substantial differences. We find that the response in $\tau$ changes both sign and magnitude over simulation time when $N_{\mathrm{d}}$ is increased. At 12:00 UTC the hourly-averaged $\tau$ response, averaged over the two responses for that hour, is 1.6 $(10 \%)$. This response decreases to $0.6(4 \%),-0.6(-6 \%)$, and finally $-1.2(-18 \%)$ for 15:00 UTC. In contrast, perturbations in $N_{\mathrm{d}}$ elicited a negative LWP response throughout simulation time.

We find the response of $\tau$ to increases in both jump properties to also be proportional to the response of LWP. Increases in $q_{\mathrm{t}}$ jump strength (decrease in free tropospheric $q_{\mathrm{t}}$ ) primarily lead to decreases in LWP and $\tau$, and increases in the $\theta$ jump strength primarily lead to increases in LWP and $\tau$. In both cases, $N_{d}$ remains relatively unchanged. When we perturb $N_{\mathrm{d}}$, we do not find this same direct proportionality between LWP and $\tau$. In general, increasing $N_{\mathrm{d}}$ in stratocumulus while holding other properties constant leads to an increase in $\tau$ (Twomey, 1977), as shown in Eq. (1). The LWP response to increasing $N_{\mathrm{d}}$ is negative (Fig. 10), the result of which is a decrease in $\tau$. When taken together the two separate effects on $\tau$ somewhat mitigate each other. This mitigation, or cancellation, has been found in other modeling studies of aerosol-cloud interactions within both marine stratiform (Ackerman et al., 2004; Wood, 2007) and marine cumuliform (Zuidema et al., 2008) cloud layers. In the simulations, the response of $\tau$ to increasing $N_{\mathrm{d}}$ is dominant at 12:00 UTC but becomes less so as the simulation continues. By 15:00 UTC impact of increasing $N_{\mathrm{d}}$ is more than offset by the response of $\tau$ to the decrease in LWP, resulting in a net negative $\tau$ response. 
The responses shown in Fig. 11 show that, within nondrizzling stratocumulus, bulk $\tau$ can be as responsive to realistic changes in the $q_{\mathrm{t}}$ and $\theta$ jumps as it is to substantial changes in aerosol and cloud droplet concentrations. However, for the purposes of understanding the climatic impact of stratocumulus, we are most interested in the impact that these perturbations in meteorological context and aerosol state have on the SW radiative forcing of the cloud layer.

\subsubsection{Cloud radiative forcing}

Because stratocumulus have a large albedo in the SW and emit LW radiation at temperatures similar to the Earth's surface, SW radiative forcing of stratocumulus at TOA is substantially larger than corresponding LW radiative forcing (Klein and Hartmann, 1993). Chen et al. (2000) determined that, averaged globally, the SW radiative forcing of these cloud layers at TOA to be almost ten times as large as their LW radiative forcing. At the surface, the globally averaged CRFs are of the same order of magnitude; shortwave radiation incident on the surface is lessened while LW emission to the surface is increased. Here we investigate the responses of both.

We computed the response of SW and LW CRF at both TOA and at the surface. For these computations we used output of thermodynamic and cloud LWC profiles, averaged over the domain and in 5-min periods, and computed the radiative fluxes at TOA and surface with or without the presence of clouds. The difference between those two computed radiative fluxes is the CRF.

We might expect that LW CRF would have a weak response to perturbations in aerosol and meteorological context when the cloud layer is optically thick in the LW but could respond more strongly when the cloud layer is optically thin (Turner et al., 2007). Because we simulate overcast, or nearly overcast, stratocumulus in this study, we would expect simulated LW CRF responses to be small. The hourlyaveraged response in LW CRF to the perturbations never exceed $2 \mathrm{~W} \mathrm{~m}^{-2}$ at TOA or at the surface (Fig. 12). At TOA, the largest hourly-averaged response is $0.8 \mathrm{~W} \mathrm{~m}^{-2}(4 \%)$, and the largest response at the surface is $-1.3 \mathrm{~W} \mathrm{~m}^{-2}(2 \%)$. For our simulated portion of the diurnal cycle, LW emission from the cloud layer to space or the surface is not substantially impacted by the perturbations we examined.

We find substantial variation in the SW CRF response across the simulations (Fig. 13). To understand this variation we must understand SW CRF in the base case. At both the surface and TOA, SW CRF is negative throughout the simulation. The changes of SW CRF with time at TOA (Fig. 13a) and at the surface (Fig. 13b) are similar, with larger negative SW CRF values at the surface because of atmospheric absorption. Solar insolation is maximum at 15:30 UTC (end of simulation), but SW CRF is strongest shortly before 14:00 UTC at $-410 \mathrm{~W} \mathrm{~m}^{-2}$. Because the cloud layer thins in response to increased SW radiative heating, the cloud layer is considerably thinner at the end of simulation and is not as reflective.

We find the SW CRF response to the perturbations, and the variations of this response with time, is quantitatively similar between TOA and the surface. Thus we focus our attention on the SW CRF response at TOA (Fig. 13a). The cloud thickens in response to increased stability at the boundary layer top when the $\theta$ jump increases, making it both more reflective and absorptive. The hourly-averaged response in SW CRF increases in magnitude from -5 and $-2 \mathrm{~W} \mathrm{~m}^{-2}$ (2 and $1 \%$ ) at $12: 00 \mathrm{UTC}$ to -12 and $-21 \mathrm{Wm}^{-2}$ (4 and $7 \%$ ) at 15:00 UTC.

In response to less moisture above the boundary layer (increase in $q_{\mathrm{t}}$ jump), the cloud layer thins and becomes less reflective and less absorptive. The CRF response increases from 2 and $1 \mathrm{Wm}^{-2}(1 \%)$ at 12:00 UTC to 59 and $26 \mathrm{Wm}^{-2}(18$ and $8 \%)$ at 15:00 UTC. For the hours centered at 14:00 and 15:00 UTC, there are large differences between the two SW CRF computed responses to moisture perturbations. These large differences illustrate how the SW CRF response can depend strongly on the reference state of the cloud system; because the BASE cloud layer is thin at these times, SW CRF is strongly dependent on changes in $q_{\mathrm{t}}$ jump strength.

Water vapor absorbs and scatters a small amount of shortwave radiation; hence modifying $q_{\mathrm{t}}$ above cloud top could affect our computations of SW CRF independent of cloud evolution. To obtain a reasonable upper bound for this effect, we investigate the change in clear-sky SW surface flux with time for the three different moisture profiles used in this study (BASE, UP MOIST and UP 2XMOIST, profiles not shown). Increasing $q_{\mathrm{t}}$ above BL within the model domain by $0.87 \mathrm{~g} \mathrm{~kg}^{-1}$ results in a decrease of $4 \mathrm{~W} \mathrm{~m}^{-2}$ in clear-sky shortwave surface flux when solar insolation is strongest (at 15:30 UTC). Not surprisingly, as solar insolation decreases, this effect decreases in an absolute sense. Thus, while the SW impact of modifications to $q_{\mathrm{t}}$ is not negligible, the impact of cloud evolution is dominant.

For increases in $N_{\mathrm{d}}$ the hourly-averaged responses in SW CRF vary between -9 and $-11 \mathrm{Wm}^{-2}(4 \%)$ at 12:00 UTC and between -1 and $44 \mathrm{Wm}^{-2}(0$ and $14 \%)$ at 15:00 UTC. As found in Fig. 11, there are opposing effects on SW CRF; increasing $N_{\mathrm{d}}$ results in a more reflective cloud while decreasing LWP results in a less reflective cloud. The impact of increasing $N_{\mathrm{d}}$ dominates cloud thinning at 12:00 UTC and cloud thinning becomes more important as the simulation progresses. The interaction between these two effects causes more non-linearity in the variation of this SW CRF response with time as compared to that from the jump properties. Similar to the results in Fig. 11, perturbations in the two jump properties can elicit changes in SW CRF on the same order of magnitude as those found for perturbations in $N_{\mathrm{d}}$.

For all perturbations, the magnitude and variation in the SW CRF response to the perturbations increases substantially at 15:00 UTC, when solar insolation is largest and the 
Table 6. Sensitivities of cloud response (liquid water path, optical depth and cloud radiative forcing) to perturbations (moisture and potential temperature jumps, cloud droplet concentration). These domain-averaged values are computed as $\frac{d \ln \text { cloud response }}{d \ln \text { perturbation }}$ for each 5-minute time period and for each perturbation (two per 5-min average). Means and standard deviations are two responses per 5-minute average and over all four hours of simulation time.

\begin{tabular}{lrrr}
\hline Cloud Response & $\begin{array}{r}\text { Increase in } \\
\text { Moisture Jump }\end{array}$ & $\begin{array}{r}\text { Increase in Potential } \\
\text { Temp. Jump }\end{array}$ & $\begin{array}{r}\text { Increase in Droplet } \\
\text { Concentration }\end{array}$ \\
\hline Liquid Water Path & $-1.12 \pm 0.48$ & $0.98 \pm 0.36$ & $-0.36 \pm 0.20$ \\
Optical Depth $(\tau)$ & $-0.94 \pm 0.41$ & $0.84 \pm 0.32$ & $-0.02 \pm 0.18$ \\
SW CRF TOA & $-0.34 \pm 0.32$ & $0.35 \pm 0.22$ & $0.01 \pm 0.08$ \\
SW CRF Surface & $-0.38 \pm 0.31$ & $0.36 \pm 0.21$ & $-0.00 \pm 0.09$ \\
LW CRF TOA & $0.24 \pm 0.03$ & $-0.08 \pm 0.03$ & $0.05 \pm 0.01$ \\
LW CRF Surface & $0.08 \pm 0.04$ & $0.03 \pm 0.04$ & $-0.01 \pm 0.01$ \\
\hline
\end{tabular}

cloud layer is thinnest. Variation in the SW CRF response substantially increases as the simulations move forward in time, behavior not found in the responses of $\tau$ (Fig. 11). For example, the smallest response in $\tau$ to increases in $\theta$ jump strength occur at 15:00 UTC, while the smallest SW CRF responses to the same increases occur at 12:00 UTC.

As compared to 12:00 UTC, when solar insolation is small, relatively small changes in $\tau$ can elicit relatively large changes in SW CRF at 15:00 UTC when solar insolation is near its diurnal peak. The dependence of SW CRF response on solar insolation may not be surprising, but is noteworthy and is not the only important factor. An incremental change in $\tau$ will elicit changes in SW CRF proportional to the amount of solar insolation and to the relative change in albedo. Solar insolation increases substantially during the simulation period, with the largest values of solar insolation occurring around 15:00 UTC. While cloud albedo is roughly proportional to $\tau$ for thicker stratocumulus $(\tau>\sim 10)$ it decreases more rapidly with $\tau$ for the values of $\tau$ we find in the last two hours of our simulations (Bohren, 1987). Figure 13 highlights the importance of time of day in determining the SW CRF response of stratiform cloud layers.

\subsubsection{Estimating constraints on jump properties for accurately observation of aerosol impacts}

Based on our simulations, we can quantitatively estimate the constraints on the independently varying cloud top jump properties necessary for the aerosol impact to be accurately observed, i.e. how "constant" meteorology must be for the aerosol effect to dominate. We define "accurately" so that the meteorological changes in SW CRF exhibit no more than $20 \%$ of the SW CRF caused by the aerosol perturbation. We use this definition to estimate the constraints for each of the two, hourly-averaged SW CRF changes (within 20\%) due to a factor of two change in aerosol concentration from the results shown in Fig. 13a. From 12:00 to 15:00 UTC, the cloud top theta and moisture jumps must be held to within $0.5,0.3,0.1$ and $0.02 \mathrm{~K}$, and $0.8,0.2,0.1$ and $0.01 \mathrm{~g} \mathrm{~kg}^{-1}$, respectively.
These values should be interpreted with appropriate caveats. These values are relevant only to our base case is the observed CIRPAS Twin Otter 19 October 2008 VOCALS case. Other stratocumulus states may exhibit very different sensitivities to meteorological context and aerosol state. We have assumed that smaller perturbations in the cloud top jump properties lead to a linearly proportional smaller CRF, which should be sufficient for an order-of-magnitude estimate. Given these caveats, the derived cloud top jump constraints are strict, less than $1 \mathrm{~K}$ and $1 \mathrm{~g} \mathrm{~kg}^{-1}$ in the early hours, and order $0.1 \mathrm{~K}$ and $0.1 \mathrm{~g} \mathrm{~kg}^{-1}$ close to solar noon. These constraints suggest that accurately observing aerosol effects in stratocumulus may be challenging, and that covariation of meteorological properties may have impacted previous observational studies of aerosol-cloud interactions.

\subsection{Computed sensitivities}

Until now, we have focused on the response of cloud properties to perturbations as defined in Sect. 5.1. However, many previous studies have computed the sensitivity of clouds to meteorology and/or aerosol, so we now report similar calculations for comparison purposes. Computed as $\frac{d \ln r e s p o n s e}{\text { dln perturbation }}$, these dimensionless values are shown in Table 6 . The values of $\frac{d \ln \tau}{d \ln N_{\mathrm{d}}}$ are in reasonable agreement with those found in other modeling studies (e.g. Lu and Seinfeld, 2005; Hill et al., 2009), keeping in mind that there can be wide variation across studies depending on meteorological context and aerosol size distribution (McComiskey et al., 2009).

Averaged over the four hour simulation period, LWP sensitivities are of the same order of magnitude between aerosol and meteorological perturbations. When we consider radiative impacts (in $\tau$ and SW CRF), the aerosol perturbations elicit sensitivities an order of magnitude lower than the meteorological perturbations. Again we can attribute this relationship to the partial mitigation occurring between changes in cloud thickness and microphysical properties when $N_{\mathrm{d}}$ increases. Cloud optical depth decreases due to cloud thinning but increases due to increases in $N_{\mathrm{d}}$, as found in other modeling studies 
(Ackerman et al., 2004; Wood, 2007; Zuidema et al., 2008). Because the magnitude of these two impacts on optical depth changes throughout the four hours of simulation, the variation in optical depth sensitivity is larger than the average value.

\section{Discussion and conclusions}

In this study we have used large-eddy simulation to examine the impact of observed variations in meteorological context $\Delta m$ and aerosol state $\Delta a$ on daytime, non-drizzling overcast stratiform evolution, and compared resulting changes in cloud properties $\Delta c$.

We first created an observationally-constrained LES based on in-situ observations taken during VOCALS. We used two different LES frameworks: one where sub-grid diffusion of scalars (e.g. moisture, energy) is accounted for (DIFF); and one where this sub-grid diffusion is neglected (NODIFF). Both frameworks were able to reasonably replicate the observed well-mixed boundary layer and its thermodynamic profiles. Because the NODIFF framework better simulated the observed circulation strength and LWP, we chose it as the basis for the experimental simulations. From this base LES we perturbed aerosol and meteorological properties and determined the cloud response. We determined realistic variations in meteorological context $\Delta m$ through use of ERAInterim data (Uppala et al., 2005, 2008), and determined variations in aerosol state spanning the observable range and in reasonable agreement with in-situ observations taken during VOCALS (Zheng et al., 2011).

We found that realistic variations in meteorological context (i.e. jump properties) can elicit responses in the cloud properties of $\tau$ and SW CRF that are on the same order of magnitude as those responses found due to realistic changes in aerosol state (i.e $N_{\mathrm{d}}$ ). In response to increases in $N_{\mathrm{d}}$, the cloud layer in the base case thinned due to increases in evaporative cooling and entrainment rate. This cloud thinning somewhat mitigates the increase in $\tau$ resulting from increases in $N_{\mathrm{d}}$. On the other hand, variations in meteorological context ( $\theta$ jump and $q_{\mathrm{t}}$ jump) did not substantially modify $N_{\mathrm{d}}$. The cloud layer thickens in response to an increase in the $\theta$ jump and thins in response to an increase in the $q_{\mathrm{t}}$ jump, both resulting in $\tau$ and SW CRF responses comparable to those found from perturbations in $N_{\mathrm{d}}$.

We directly computed LW and SW CRF responses to aerosol and meteorological perturbations. Longwave CRF was not substantially altered by the perturbations we tested, while SW CRF could be modified by as much as $18 \%$ by the perturbations. The variation in absolute SW CRF responses was relatively small during the morning hours and increased as solar insolation increased and $\tau$ decreased. This variation highlights the importance of time of day in determining the SW CRF response of stratiform cloud layers to changes in meteorology and aerosol.
We note that our perturbations in moisture and potential temperature jump are underestimated as compared to observations (see Sect. 5.1). If we did not capture the real variability in the jump properties through our use of reanalysis data, the magnitude of our associated cloud responses might also be underestimated. This possible underestimation would further strengthen our conclusion: variations in meteorological context can elicit cloud radiative responses on par or larger than those from variations in aerosol state.

Although our conclusions are based on a consistent modeling framework, and the simulations are derived from realistic observations, there are a few important caveats of note. First, we held large-scale subsidence constant across all the simulations (see Table 1). Bretherton et al. (2004) found a diurnal variation in large-scale subsidence for Southeast Pacific stratocumulus, and Caldwell and Bretherton (2009) found it important to simulate this diurnal variation in subsidence to accurately simulate the diurnal cycle of stratocumulus in this region. This variation can influence the LWP and cloud fraction within coastal stratocumulus, and we did not account for this variation.

As we noted previously, choices of spatial and temporal model resolutions can influence LES representation of the STBL (e.g. Cheng et al., 2010). Additionally, we did not examine changes in cloud responses due to co-varying aerosol and meteorological properties, and these interactions could play important roles in modifying the cloud responses we found. This examination is left for future study.

That we find the cloud radiative response to be dependent on the time of day suggests that observations of such responses for only certain times of the day, e.g. from aircraft or polar-orbiting satellite, may not be representative of the full day. These variations in time of day may have to be accounted for when studying cloud responses to meteorology and/or aerosol. Analyses of the diurnal cycle of stratocumulus using geostationary satellites (e.g. Painemal et al., 2012) are useful in understanding the importance of sampling time from polar-orbiting satellites. Similar analyses may prove useful in better understanding the importance of time-of-day for observational campaigns via aircraft.

Our estimates of the limits on variability of cloud top jump properties necessary for accurate observation of aerosol SW radiative impacts on stratocumulus reveal strict constraints: less than $1 \mathrm{~K}$ and $1 \mathrm{~g} \mathrm{~kg}^{-1}$ in the early morning hours, and order $0.1 \mathrm{~K}$ and $0.1 \mathrm{~g} \mathrm{~kg}^{-1}$ close to solar noon.

We addressed the core questions in our introduction using a modeling framework at a cloudscale process level. Nevertheless, we arrive at a conclusions similar to those of other analyses of large-scale Southeast Pacific satellite data. Meteorological variability is important in determining the stratocumulus radiative response (Painemal and Zuidema, 2010) and variations in meteorological context can obfuscate the impact of aerosol perturbations on stratocumulus evolution (George and Wood, 2010). 
Acknowledgements. This research was supported by Office of Naval Research grant N00014-08-1-0437. We thank Robert Wood for helpful comments and suggestions. Computer resources were provided by the UC-Santa Cruz Climate Change and Impacts Laboratory. We are especially grateful for computer and technical support from Eli Morris and Mark Snyder. We also sincerely appreciate the efforts of three anonymous referees. Their comments and suggestions led to substantial improvements in this manuscript.

Edited by: B. Albrecht

\section{References}

Ackerman, A., VanZanten, M. C., Stevens, B., Savic-Jovcic, V., Bretherton, C. S., Chlond, A., Golaz, J.-C., Jiang, H., Khairoutdinov, M., Kreuger, S. K., Lewellen, D. C., Lock, A., Moeng, C.-H., Nakamura, K., Petters, M. D., Snider, J. R., Weinbrecht, S., and Zulauf, M.: Large-eddy simulations of a drizzling, stratocumulus-topped marine boundary layer, Mon. Weather Rev., 137, 1083-1110, 2009.

Ackerman, A. S., Kirkpatrick, M. P., Stevens, D. E., and Toon, O. B.: The impact of humidity above stratiform clouds on indirect aerosol climate forcing, Nature, 432, 1014-1017, 2004.

Albrecht, B. A.: Aerosols, cloud microphysics and fractional cloudiness, Science, 245, 1227-1230, 1989.

Bohren, C.: Multiple scattering of light and some of it observable consequences, Amer. J. Phys., 55, 524-533, 1987.

Brenguier, J.-L., F. B. and Geoffroy, O.: Cloud optical thickness and liquid water path - does the $k$ coefficient vary with droplet concentration?, Atmos. Chem. Phys., 11, 9771-9786, doi:10.5194/acp-11-9771-2011, 2011.

Brenguier, J.-L., Chuang, P. Y., Fouquart, Y., Johnson, D. W., Parol, F., Pawlowska, H., Pelon, J., Schüller, L., Schröder, F., and Snider, J.: An overview of the ACE-2 CLOUDYCOLUMN closure experiment, Tellus, 52B, 815-827, 2000.

Brenguier, J.-L., Pawlowska, H., and Schüller, L.: Cloud microphysical and radiative properties for parameterization and satellite monitoring of the indirect effect of aerosol on climate, J. Geophys. Res., 108, D158632, doi:10.1029/2002JD002682, 2003.

Bretherton, C., Uchida, J., and Blossey, P.: Slow manifolds and multiple equilibria in stratocumulus-capped boundary layers, J. Adv. Model. Earth Syst., 2, 20 pp., doi:10.3894/JAMES.2010.2.14, 2010.

Bretherton, C. S., MacVean, M., Bechtold, P., Chlond, A., Cotton, W., Cuxart, J., Cuijpers, H., Khairoutdinov, M., Kosovic, B., Lewellen, D., Hoh Moeng, C., Siebesma, P., Stevens, B., Stevens, D., Sykes, I., and Wyant, M.: An intercomparison of radiativelydriven entrainment and turbulence in a smoke cloud, as simulated by different numerical models, Q. J. Roy. Meteor. Soc., 125, 391423, 1999.

Bretherton, C. S., Uttal, T., Fairall, C. W., Yuter, S. E., Weller, R. A., Baumgardner, D., Comstock, K., Wood, R., and Raga, G. B.: The EPIC 2001 stratocumulus study, B. Am. Meteor. Soc., 85, 967977, 2004.

Bretherton, C. S., Blossey, P. N., and Uchida, J.: Cloud droplet sedimentation, entrainment efficiency, and subtropical stratocumulus albedo, Geophys. Res. Let., 34, L03813, doi:10.1029/2007GL027648, 2007.
Cahalan, R. F., Oreopoulos, L., Marshak, A., Evans, K. F., Davis, A. B., Pincus, R., Yetzer, K. H., Mayer, B., Davies, R., Ackerman, T. P., Barker, H. W., Clothiaux, E. E., Ellingson, R. G., Garay, M. J., Kassianov, E., Kinne, S., Macke, A., O'Hirok, W., Partain, P. T., Prigarin, S. M., Rublev, A. N., Stephens, G. L., Szczap, F., Takara, E. E., Várnai, T., Wen, G., and Zhuravleva, T. B.: The I3RC: Bringing together the most advanced radiative transfer tools for cloudy atmospheres, B. Am. Meteor. Soc., 86, 1275-1293, 2005.

Caldwell, P. and Bretherton, C. S.: Large eddy simulation of the diurnal cycle in southeast Pacific stratocumulus, J. Atmos. Sci., 66, 432-449, doi:10.1175/2008JAS2785.1, 2009.

Chen, T., Rossow, W. B., and Zhang, Y.: Radiative effects of cloudtype variations, J. Climate, 13, 264-286, 2000.

Cheng, A., Xu, K.-M., and Stevens, B.: Effects of resolution on the simulation of boundary-layer clouds and the partition of kinetic energy to subgrid scales, J. Adv. Model. Earth Syst., 2, 21 pp., doi:10.3894/JAMES.2010.2.3, 2010.

Chuang, P. Y., Saw, E. W., Small, J. D., Shaw, R. A., Sipperley, C. M., Payne, G. A., and Bachalo, W. D.: Airborne phase doppler interferometry for cloud microphysical measurements, Aerosol Sci. Tech., 42, 685-703, doi:10.1080/02786820802232956, 2008.

Coakley, J. A., Bernstein, R. L., and Durkee, P. A.: Effect of shipstack effluents on cloud reflectivity, Science, 237, 1020-1022, 1987.

Cole, J. N. S.: Assessing the importance of unresolved cloudradiation interactions in atmospheric global climate models using the multiscale-modelling framework., Ph.D. thesis, The Pennsylvania State University, State College, PA 16801, USA, 2005.

Cotton, W., Sr., R. A. P., Walko, R. L., Liston, G. E., Tremback, C. J., Jiang, H., McAnelly, R. L., Harrington, J., Nicholls, M. E., Carrio, G. G., and McFadden, J. P.: RAMS 2001: Current status and future directions, Meteor. Atmos. Phys., 82, 5-29, 2003.

Deardorff, J. W.: Stratocumulus-Capped Mixed Layers Derived from a Three-Dimensional Model, Bound.-Layer Meteor., 18, 495-527, 1980.

Durkee, P. A., Noone, K. J., Ferek, R. J., Johnson, D. W., Taylor, J. P., Garrett, T. J., Hobbs, P. V., Hudson, J. G., Bretherton, C. S., Innis, G., Frick, G. M., Hoppel, W. A., O’Dowd, C. D., Russell, L. M., Gasparovic, R., Nielsen, K. E., Tessmer, S. A., Öström, E., Osborne, S. R., Flagan, R. C., Seinfeld, J. H., and Rand, H.: The impact of ship-produced aerosols on the microstructure and albedo of warm marine stratocumulus clouds: a test of MAST hypothesis 1i and 1ii, J. Atmos. Sci., 57, 2554-2569, 2000.

Dyunkerke, P. G., de Roode, S. R., VanZanten, M. C., Calvo, J., Cuxart, J., Cheinet, S., Chlond, A., Grenier, H., Jonker, P. J., Köhler, M., Lenderink, G., Lewellen, D., Lappen, C.-L., Lock, A. P., Moeng, C.-H., Müller, F., Olmeda, D., Piriou, J.-M., Sánchez, E., and Sednev, I.: Observations and numerical simulations of the diurnal cycle of the EUROCS stratocumulus case, Q. J. Roy. Meteorol. Soc., 130, 3269-3296, 2004.

Feingold, G., Tzivion, S., , and Levin, Z.: Evolution of raindrop spectra. Part I: solution to the stochastic collection/breakup equation using the method of moments, J. Atmos. Sci., 44, 33873399, 1988.

Feingold, G., Stevens, B., Cotton, W. R., and Frisch, A. S.: The relationship between drop in-cloud residence time and drizzle production in numerically simulated stratocumulus clouds, J. At- 
mos. Sci., 53, 1108-1122, 1996.

Garrett, T. J. and Zhao, C.: Increased arctic cloud longwave emissivity associated with pollution from mid-latitudes, Nature, 440, 787-789, 2006

George, R. C. and Wood, R.: Subseasonal variability of low cloud radiative properties over the southeast Pacific Ocean, Atmos. Chem. Phys., 10, 4047-4063, doi:10.5194/acp-10-4047-2010, 2010.

Ghate, V. P., Albrecht, B. A., Kollias, P., Jonsson, H. H., and Breed, D. W.: Evaluation of the aerosol indirect effect in marine stratocumulus clouds: droplet number, size, liquid water path, and radiative impact, Geophys. Res. Lett., 110, L14807, doi:10.1029/2007GL029748, 2007.

Han, Q., Rossow, W. B., Chou, J., and Welch, R. M.: Global survey of the relationships of cloud albedo and liquid water path with droplet size using ISCCP, J. Climate, 11, 1516-1528, 1998.

Harrington, J.: The Effects of Radiative and Microphysical Processes on Simulated Warm and Transition Season Arctic Stratus, Ph.D. thesis, Colorado State University, Ft. Collins CO, 80523, USA, 1997.

Harrington, J. Y. and Olsson, P. Q.: A Method for the Parameterization of Cloud Optical Properties in Bulk and Bin Microphysical Models: Implications for Arctic Cloudy Boundary Layers, Atmos. Res., 57, 51-80, 2001.

Harrington, J. Y., Feingold, G., and Cotton, W. R.: Radiative impacts on the growth of a population of drops within simulated summertime arctic stratus, J. Atmos. Sci., 57, 766-785, 2000.

Hill, A. A., Dobbie, S., and Yin, Y.: The impact of aerosols on nonprecipitating marine stratocumulus. I: Model description and prediction of the indirect effect, Q. J. Roy. Meteor. Soc., 134, 11431154, 2008.

Hill, A. A., Feingold, G., and Jiang, H.: The influence of entrainment and mixing assumption on aerosol-cloud interactions in marine stratocumulus, J. Atmos. Sci., 66, 1450-1464, 2009.

Jiang, H., Feingold, G., and Cotton, W. R.: Simulations of aerosol-cloud-dynamical feedbacks resulting from entrainment of aerosol into the marine boundary layer during the Atlantic stratocumulus transition experiment, J. Geophys. Res., 107, 4813, doi:10.1029/2001JD001502, 2002.

Kaufman, Y. J., Koren, I., Remer, L. A., Rosenfeld, D., and Rudich, Y.: The effect of smoke, dust, and pollution aerosol on shallow cloud development over the Atlantic Ocean, Proc. Natl. Acad. Sci., 102, 11207-11212, doi:10.1073/pnas.0505191102, 2005.

Klein, S. A. and Hartmann, D. L.: The Seasonal Cycle of Low Stratiform Clouds, J. Climate, 6, 1587-1606, 1993.

Lewellen, D. and Lewellen, W.: Large-eddy boundary layer entrainment, J. Atmos. Sci., 55, 2645-2665, 1998.

Lilly, D. K.: Models of Cloud Topped Mixed Layers under a Strong Inversion, Q. J. Roy. Meteor. Soc., 94, 292-309, 1968.

Lilly, D. K.: Entrainment into mixed layers. Part II: A new closure, J. Atmos. Sci., 59, 3353-3361, 2002.

Lu, M.-L. and Seinfeld, J. H.: Study of the aerosol indirect effect by large-eddy simulation of marine stratocumulus, J. Atmos. Sci., 62, 3909-3932, 2005.

Lu, M.-L., Conant, W. C., Jonsson, H. H., Varutbangkul, V., Flagan, R. C., and Seinfeld, J. H.: The Marine Stratus/Stratocumulus Experiment: aerosol-cloud relationships in marine stratocumulus, J. Geophys. Res., 112, 209, doi:10.1029/2006JD007985, 2007.
Matsui, T., Masunaga, H., Kreidenweis Sr., S. M.,, R. A. P., Tao, W.-K., Chin, M., and Kaufman, Y. J.: Satellite-based assessment of marine low cloud variability associated with aerosol, atmospheric stability, and the diurnal cycle, J. Geophys. Res., 111, D17204, doi:10.1029/2005JD006097, 2006.

McClatchy, R., Fenn, R., Selby, J., Voltz, F., and Garing, J.: Optical Properties of the Atmosphere, Tech. rep., Air Force Cambridge Research Laboratories, Bedford, MA, Environmental Research Papers, No. 411, 1971.

McComiskey, A., Feingold, G., Frisch, A., Turner, D., Miller, M., Chu, J., Min, Q., and Ogren, J.: An assessment of aerosol-cloud interactions in marine stratus clouds based on surface remote sensing, J. Geophys. Res., 114, D09203, doi:10.1029/2008JD011006, 2009.

Mechem, D. B., Yuter, S. E., and DeSzoeke, S. P.: Thermodynamic and Aerosol Controls in Southeast Pacific Stratocumulus, J. Atmos. Sci., 69, 1250-1266, doi:10.1175/JAS-D-11-0165.1, 2012.

Mellado, J. P.: The evaporatively driven cloud-top mixing layer, J. Fluid Mech., 660, 5-36, doi:10.1017/S0022112010002831, 2010.

Miles, N. L., Verlinde, J., and Clothiaux, E. E.: Cloud droplet size distributions in low-level stratiform clouds, J. Atmos. Sci., 57, 295-311, 2000.

Nakajima, T., King, M. D., Spinhirne, J. D., and Radke, L. F.: Determination of the optical thickness and effective particle radius of clouds from reflected solar radiation measurements. Part II: Marine stratocumulus observations, J. Atmos. Sci., 48, 728-750, 1991.

Nicholls, S.: The Structure of Radiatively Driven Convection in Stratocumulus, Q. J. Roy. Meteor. Soc., 115, 487-511, 1989.

Painemal, D. and Zuidema, P.: Microphysical variability in southeast Pacific stratocumulus clouds: synoptic conditions and radiative response, Atmos. Chem. Phys., 10, 6255-6269, doi:10.5194/acp-10-6255-2010, 2010.

Painemal, D., Minnis, P., Ayers, J. K., and O'Neill, L.: GOES-10 microphysical retrievals in marine warm clouds: Multi-instrument validation and daytime cycle over the southeast Pacific, J. Geophys. Res., 117, D19212, doi:10.1029/2012JD017822, 2012.

Petters, J. L., Harrington, J. Y., and Clothiaux, E. E.: Radiativedynamical Feedbacks in Low Liquid Water Path Stratiform Clouds, J. Atmos. Sci., 69, 1498-1512, doi:10.1175/JAS-D-110169.1, 2012.

Pinsky, M., Magaritz, L., Khain, A., Krasnov, O., and Sterkin, A.: Investigation of droplet size distributions and drizzle formation using a new trajectory ensemble model. Part I: model description and first results in a nonmixing limit, J. Atmos. Sci., 65, 2064 2086, doi:10.1175/2007JAS2486.1, 2008.

Quaas, J., Boucher, O., and Lohmann, U.: Constraining the total aerosol indirect effect in the LMDZ and ECHAM4 GCMs using MODIS satellite data, Atmos. Chem. Phys., 6, 947-955, doi:10.1029/2007JD008962, 2006.

Rahn, D. A. and Garreaud, R.: Marine boundary layer over the subtropical southeast Pacific during VOCALS-REx - Part 2: synoptic variability, Atmos. Chem. Phys., 10, 4507-4519, doi:10.5194/acp-10-4507-2010, 2010.

Randall, D., Bony, S., Colman, R., Fichefet, T., Fyfe, J., Kattsov, V., Pitman, A., Shukla, J., Srinivasan, J., Stouffer, R., Sumi, A., and Taylor, K.: Climate Change 2007: The Physical Science 
Basis, Contribution of Working Group I to the Fourth Assessment Report of the Intergovernmental Panel on Climate Change, chap. Climate models and their evaluation, Cambridge University Press, Cambridge, edited by: Solomon, S., Qin, D., Manning, M., Chen, Z., Marquis, M., Averyt, K. B., Tignor, M., and Miller, H. L., 2007.

Sandu, I., Brenguier, J.-L., Geoffroy, O., Thouron, O., and Masson, V.: Aerosol impacts on the diurnal cycle of marine stratocumulus, J. Atmos. Sci., 65, 2705-2718, 2008.

Schubert, W. H., Wakefield, J. S., Steiner, E. J., and Cox, S. K.: Marine Stratocumulus Convection. Part II: Horizontally Inhomogeneous Solutions, J. Atmos. Sci., 36, 1308-1324, 1979.

Seinfeld, J. and Pandis, S.: Atmospheric Chemistry and Physics: From Air Pollution to Climate Change., John Wiley and Sons, New York, 1998.

Sekiguchi, M., Nakajima, T., Suzuki, K., Kawamoto, K., Higurashi, A., Rosenfeld, D., Sano, I., and Mukai, S.: A study of the direct and indirect effects of aerosol using global satellite data sets of aerosol and cloud parameters, J. Geophys. Res., 108, 4699, doi:10.1029/2002JD003359, 2003.

Stevens, B. and Feingold, G.: Untangling aerosol effects on clouds and precipitation in a buffered system, Nature, 461, 607-613, doi:10.1038/nature08281, 2009.

Stevens, B., Feingold, G., Cotton, W. R., and Walko, R. L.: Elements of the microphysical structure of numerically simulated nonprecipitating stratocumulus, J. Atmos. Sci., 53, 980-1007, 1996.

Stevens, B., Cotton, W. R., Feingold, G., and Moeng, C.H.: Large-Eddy Simulations of strongly precipitating, shallow, stratocumulus-topped boundary layers, J. Atmos. Sci., 55, 36163638, 1998.

Stevens, B., Moeng, C.-H., Ackerman, A. S., Bretherton, C. S., Chlond, A., DeRoode, S., Edwards, J., Golaz, J.-C., Jiang, H., Khairoutdinov, M., Kirkpatrick, M. P., Lewellen, D. C., Lock, A., Müller, F., Stevens, D. E., Whelan, E., and Zhu, P.: Evaluation of Large-Eddy Simulations via Observations of Nocturnal Marine Stratocumulus, Mon. Weather Rev., 133, 1443-1462, 2005.

Sullivan, P., Moeng, C.-H., Stevens, B., Lenschow, D. H., and Mayor, S. D.: Structure of the entrainment zone capping the convective planetary boundary layer, J. Atmos. Sci., 55, 3042-3064, 1998.

Sun, J. and Wang, Y.: Effect of the entrainment flux ratio on the relationship between entrainment rate and convective Richardson number, Bound.-Layer Meteor., 126, 237-247, doi:10.1007/s10546-007-9231-4, 2008.

Teller, A. and Levin, Z.: Factorial method as a tool for estimating the relative contribution to precipitation of cloud microphysical processes and environmental conditions: Method and application, J. Geophys. Res., 113, D02202, doi:10.1029/2007JD008960, 2008.

Turner, D. D., Vogelmann, A. M., Austin, R. T., Barnard, J. C., Cady-Pereira, K., Chiu, J. C., Clough, S. A., Flynn, C., Khaiyer, M. M., Liljegren, J., Johnson, K., Lin, B., Long, C., Marshak, A., Matrosov, S. Y., McFarlane, S. A., Miller, M., Min, Q., Minnis, P., O'Hirok, W., Wang, Z., and Wiscombe, W.: Thin liquid water clouds: their importance and their challenge, B. Am. Meteor. Soc., 88, 177-190, 2007.

Twohy, C. H., Petters, M. D., Snider, J. R., Stevens, B., Tahnk, W., Wetzel, M., Russell, L., and Burnet, F.: Evaluation of the aerosol indirect effect in marine stratocumulus clouds: droplet number, size, liquid water path, and radiative impact, J. Geophys. Res., 110, D08203, doi:10.1029/2004JD005116, 2005.

Twomey, S. A.: The influence of pollution on the shortwave albedo of clouds, J. Atmos. Sci., 34, 1149-1152, 1977.

Twomey, S. A. and Wojciechowski, T.: Observations of the geographical variation of cloud nuclei, JAS, 26, 684-688, 1969.

Tzivion, S., Feingold, G., and Levin, Z.: An Efficient Numerical Solution to the Stochastic Collection Equation, J. Atmos. Sci., 44, 3139-3149, 1987.

Tzivion, S., Feingold, G., and Levin, Z.: The evolution of rain-drop spectra. Part II: Collisional collection/breakup and evaporation in a rain shaft, J. Atmos. Sci., 46, 3312-3327, 1989.

Uppala, S. M., Kaallberg, P., Simmons, A. J., Andrae, U., Bechtold, V. D. C., Fiorino, M., Gibson, J. K., Haseler, J., Hernandez, A., Kelly, G. A., Li, X., Onogi, K., Saarinen, S., Berg, L. V. D., Bidlot, J., Bormann, N., Caires, S., Chevallier, F., Dethof, A., Dragosavac, M., Fisher, M., Fuentes, M., Hagemann, S., Hólm, E., Hoskins, B. J., Isaken, L., Janssen, P. A. E. M., Jenne, R., McNally, A. P., Mahfouf, J.-F., Morcrette, J.-J., Rayner, N. A., Saunders, R. W., Simon, P., Sterl, A., Trenberth, K. E., Untch, A., Vasiljevic, D., Viterbo, P., and Woollen, J.: The ERA40 re-analysis, Q. J. Roy. Meteor. Soc., 131, 2961-3012, doi:10.1256/qj.04.176, 2005.

Uppala, S. M., Dee, D., Kobayashi, S., Berrisford, P., and Simmons, A.: Towards a climate data assimilation system: status update of ERA-Interim, ECMWF Newslett., 115, 12-19, 2008.

Wang, H., Feingold, G., Wood, R., and Kazil, J.: Modelling microphysical and meteorological controls on precipitation and cloud cellular structures in Southeast Pacific stratocumulus, Atmos. Chem. Phys., 10, 6347-6362, doi:10.5194/acp-10-6347-2010, 2010.

Wang, S., Wang, Q., and Feingold, G.: Turbulence, condensation, and liquid water transport in numerically simulated nonprecipitating stratocumulus clouds, J. Atmos. Sci., 60, 262-278, 2003.

Wendisch, M., Garrett, T. J., and Strapp, J. W.: Wind tunnel tests of the airborne PVM-100A response to large droplets, J. Atmos. Ocean. Tech., 19, 1577-1584, 2002.

Wood, R.: Cancellation of aerosol indirect effects in marine stratocumulus through cloud thinning, J. Atmos. Sci., 64, 26572669, 2007.

Wood, R., Mechoso, C. R., Bretherton, C. S., Weller, R. A., Huebert, B., Straneo, F., Albrecht, B. A., Coe, H., Allen, G., Vaughan, G., Daum, P., Fairall, C., Chand, D., Klenner, L. G., Garreaud, R., Grados, C., Covert, D. S., Bates, T. S., Krejci, R., Russell, L. M., de Szoeke, S., Brewer, A., Yuter, S. E., Springston, S. R., Chaigneau, A., Toniazzo, T., Minnis, P., Palikonda, R., Abel, S. J., Brown, W. O. J., Williams, S., Fochesatto, J., Brioude, J., and Bower, K. N.: The VAMOS Ocean-Cloud-AtmosphereLand Study Regional Experiment (VOCALS-REx): goals, platforms, and field operations, Atmos. Chem. Phys., 11, 627-654, doi:10.5194/acp-11-627-2011, 2011.

Wyant, M. C., Wood, R., Bretherton, C. S., Mechoso, C. R., Bacmeister, J., Balmaseda, M. A., Barrett, B., Codron, F., Fast, J., Kaiser, J. W., Kitagawa, H., Klein, S. A., Kohler, M., Manganello, J., Pan, H.-L., Sun, F., Wang, S., and Wang, Y.: The PreVOCA experiment: modeling the lower troposphere in the Southeast Pacific, Atmos. Chem. Phys., 10, 4757-4774, doi:10.5194/acp-10-4757-2010, 2010. 
Xu, K.-M. and Randall, D. A.: Impact of interactive radiative transfer on the macroscopic behavior of cumulus ensembles: Part I: radiation parameterization and sensitivity tests, J. Atmos. Sci., 52, 785-799, 1995.

Xue, H. and Feingold, G.: Large-eddy simulations of trade wind cumuli: investigation of aerosol indirect effects, J. Atmos. Sci., 60, 1605-1622, 2006.

Zheng, X., Albrecht, B., Jonsson, H. H., Khelif, D., Feingold, G., Minnis, P., Ayers, K., Chuang, P., Donaher, S., Rossiter, D., Ghate, V., Ruiz-Plancarte, J., and Sun-Mack, S.: Observations of the boundary layer, cloud and aerosol variability in the southeast Pacific near-coastal marine stratocumulus during VOCALSREx, Atmos. Chem. Phys., 11, 9943-9959, doi:10.5194/acp-119943-2011, 2011.
Zuidema, P., Xue, H., and Feingold, G.: Shortwave radiative impacts from aerosol effects on marine shallow cumuli, J. Atmos. Sci., 65, 1979-1990, 2008. 